\title{
Peptide-Like Molecules (PLMs): A Journey from Peptide Bond Isosteres to Gramicidin S Mimetics and Mitochondrial Targeting Agents
}

\author{
Peter Wipf*, Jingbo Xiao, and Corey R. J. Stephenson
}

\begin{abstract}
Peptides are natural ligands and substrates for receptors and enzymes and exhibit broad physiological effects. However, their use as therapeutic agents often suffers from poor bioavailability and insufficient membrane permeability. The success of peptide mimicry hinges on the ability of bioisosteres, in particular peptide bond replacements, to adopt suitable secondary structures relevant to peptide strands and position functional groups in equivalent space. This perspective highlights past and ongoing studies in our group that involve new methods development as well as specific synthetic library preparations and applications in chemical biology, with the goal to enhance the use of alkene and cyclopropane peptide bond isosteres.
\end{abstract}

Keywords: Alkene peptide bond isosteres · Cyclopropanes · Gramicidin S - Mitochondrial targeting · Organic synthesis

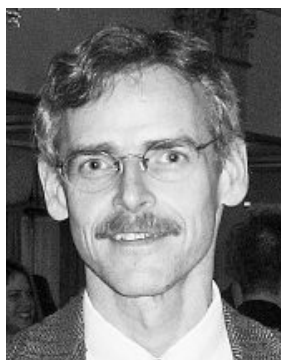

Peter Wipf was born in Aarau, Switzerland. He received his Dipl. Chem. in 1984 and his $\mathrm{PhD}$ in 1987 from the University of Zurich under the direction of Professor Heinz Heimgartner. After a Swiss NSF postdoctoral fellowship with Professor Robert E. Ireland at the University of Virginia, Wipf began his appointment at the University of Pittsburgh in the fall of 1990. His research interests include the total synthesis of natural products, organometallic and heterocyclic chemistry, combinatorial, medicinal and computational chemistry. His group studies chemical reactivity and the use of synthesis to augment the chemical toolbox and develop new therapeutic strategies. The discovery of fundamentally new reaction pathways is stimulated by exploratory studies of transition metal complexes, in particular zirconocenes.

\footnotetext{
${ }^{*}$ Correspondence: Prof. Dr. P. Wipf

University of Pittsburgh

Department of Chemistry

Center for Chemical Methodologies \& Library

Development

Pittsburgh, PA 15260

Tel.: +1 4126248606

Fax: +1412 6240787

E-mail: pwipf@pitt.edu
}

\section{Introduction}

Biopolymers represent a special class of natural products, offering unique opportunities for small molecule mimicry. Biopolymer-derived compounds can exploit drug-target contacts that closely parallel those found in native systems, such as protein-protein and proteinlipid interactions. This gross structural homology can often be advantageous in developing new drug leads; i.e. synthetic materials can be more readily recognized and integrated into native biochemical processes. Moreover, physiological biopolymer degradation typically leads to metabolites that are tolerated in vivo and readily excreted. However, hydrolytic degradation is also among the native biochemical processes that often function to limit drug lifetime. These considerations, as well as the inherent difficulties of biopolymers to pass through membranes, have been among the prime contributory factors driving the development of synthetic biopolymer surrogates. Ideally, the latter can mimic the tertiary structure and function of native materials while, simultaneously, displaying immunity to hydrolytic degradation and taking advantage of active or passive membrane transfer processes.

Significantly, synthetic biopolymerinspired materials either composed of or incorporating unnatural $\alpha-, \beta-$, and $\gamma-$ amino acids, peptoids, peptide isosteres, and other amino acid surrogates have already been found to exhibit folding behaviors similar to native peptides, to be effective disruptors of protein-protein interactions, and, in many instances, allowing for useful therapeutic activities. A Sunesis-Merck collaboration discovered aminoethylene isosteres $\mathbf{1}$ as potent inhibitors of the $\beta$-site amyloid precursor protein cleaving enzyme (Fig. 1). ${ }^{[1]}$ The selective cathepsin $\mathrm{K}$ inhibitor 2, developed by a Celera-Merck team, featured a trifluoroethylamine isostere developed by Zanda's group. ${ }^{[2,3]}$ The Fujii group at Kyoto University has a long tradition in developing methodology for $(E)$-alkene peptide isostere synthesis, and recently reported cyclic RGD mimetics 3 based on this concept. ${ }^{[4]}$ Another creative design for amide bond replacements is being pursued by the Sieburth group at Temple University, which yielded 4, a silanediolbased inhibitor of angiotensin-converting enzyme. ${ }^{[5]}$

With the goal of developing a unified approach toward constructing biopolymer surrogates, we have exploited new reaction technologies developed in our laboratory for generating structurally diverse biopolymer-like compounds, specifically peptide-like molecules (PLMs). Our building blocks include cyclopropane-substituted $\delta$ - and $\gamma$-amino acids, $\beta, \gamma$-unsaturated $\delta$-amino acids, $\beta$-substituted $\beta$-amino acids, and $\alpha, \beta$-disubstituted $\beta$-amino acids; with structural diversity originating both from building block diversity as well as sequence diversity. In addressing the latter, each of these building block families are readily incorporated into standard peptide synthesis protocols, thereby, accelerating 


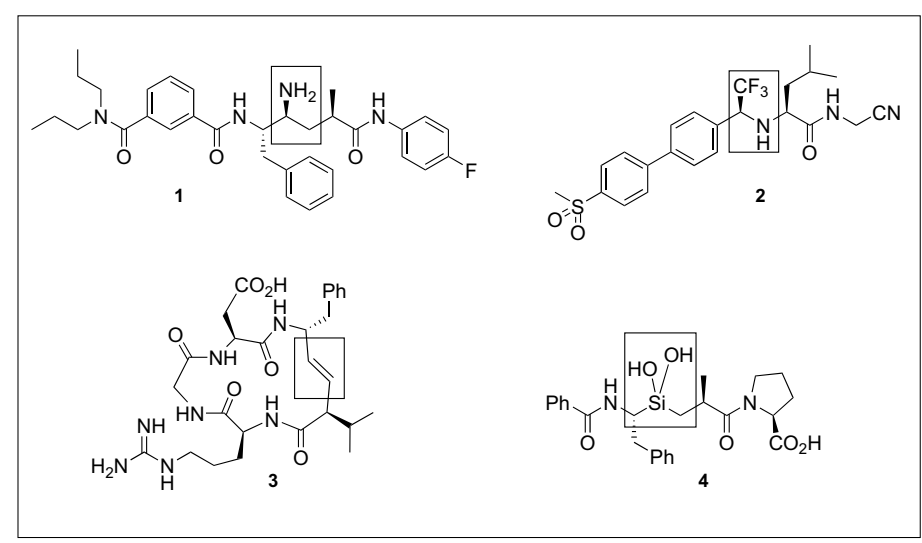

Fig. 1. Recent examples of biologically active peptide bond isosteres.

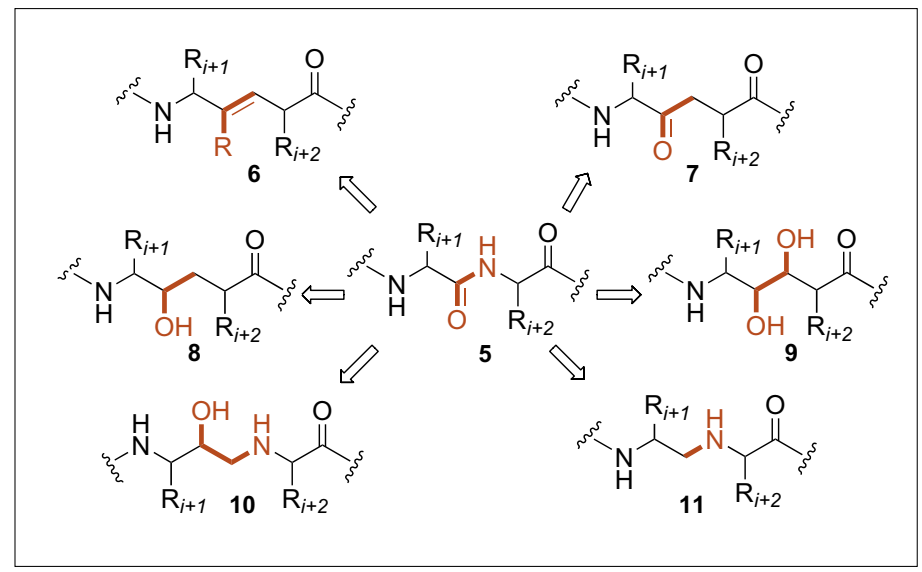

Fig. 2. Amide bond linkage in peptides (5) and common isosteric replacements 6-11. access to the targeted biological pathway disruptors and functional mimetics.

In recent years, $\beta$ - and $\gamma$-amino acids ${ }^{[6]}$ have been studied extensively, and, due to a greater understanding of their folding properties coupled with the power of chemical genetics, ${ }^{[7]}$ the structure-based $\operatorname{design}^{[8]}$ of new therapeutic agents has been enabled. Much like their natural $\alpha$-amino counterparts, $\beta$ - and $\gamma$-amino acids have been found to form a variety of helical and pleated sheet-like structural motifs. Oligomers that adopt predictable conformations in aqueous solution are accessible via modular chemistry and enable the display of a wide range of functional groups, which renders them attractive for creating new types of biologically active agents. [9] This concept has been validated and broadly popularized with $\beta$-peptides. ${ }^{[10]} \beta$-Peptide-based foldamers provide access to a variety of backbone conformations, including the 14-helix. $\beta$-Peptides can display antibacterial[11] and antifungal[12] activities, permeate cell membrane, ${ }^{[13]}$ block protein-protein interactions, ${ }^{[14]}$ self-assemble into helixbundle quaternary structures, ${ }^{[15]}$ and form lyotropic liquid crystalline phases. ${ }^{[16]}$ These applications have firmly established that conformational preorganization, the ability to arrange side chains in a specific three-dimensional architecture, is critical to accomplishing well-defined macroscopic physical or biological properties. The promising range of applications for foldamers that are not exclusively composed of the standard $\alpha$-amino acid residues justifies a further expansion to include $\gamma$-and $\delta$-amino acids and composites of mixed constitution. In all cases, it is critical to develop new synthetic methodologies that allow rapid and scaleable access to these materials as well as perform fundamental studies elucidating the factors that influence secondary structure.

PLMs with $\gamma$ - and $\delta$-amino acid residues have been studied much less than the corresponding $\beta$-peptides, but there is little doubt that these derivatives offer similarly enticing opportunities for supramolecular chemistry and drug discovery. ${ }^{[17]}$ We have developed versatile and innovative approaches toward these compound classes, and we can now readily expand on this chemistry; introduce additional, more polar substituents into our scaffolds; generate libraries of oligomeric structures for the study of their biological effects and structural features; and prepare novel steroid and glycoside chimeras. ${ }^{[18,19]}$

\section{Peptide-like Molecules (PLMs)}

Peptides exhibit broad physiological effects and are natural ligands for receptors and enzymes. Recently, considerable advances have been made in the targeted delivery of peptides, and their appeal as pharmaceuticals is surging. ${ }^{[20]}$ Modifications of native peptide sequences and introduction of bioisosteres represent complementary strategies to harness desirable biological effects. The success of peptide mimicry hinges on the ability of bioisosteres, in particular peptide bond replacements, to adopt suitable secondary structures relevant to peptide strands and position functional groups into equivalent space.

The replacement of the scissile peptide bond $\mathbf{5}$ with nonhydrolyzable isosteric functions is an important design motif in medicinal chemistry. ${ }^{[21]}$ In recent years, many nonhydrolyzable mimetics have been developed, including $(E)$-alkene $(\psi[(E)-\mathrm{C}(\mathrm{R})=\mathrm{CH}]) \mathbf{6}^{[22]}$ ketomethylene $\left(\psi\left[\mathrm{COCH}_{2}\right]\right)$ 7, ${ }^{[23]}$ hydroxyethylene $\left(\psi\left[\mathrm{CH}(\mathrm{OH}) \mathrm{CH}_{2}\right]\right) \mathbf{8}^{\text {,24] }}$ dihydroxyethylene $(\psi[\mathrm{CH}(\mathrm{OH}) \mathrm{CHOH}])$ 9,[25] hydroxyethylamine $\left(\psi\left[\mathrm{CH}(\mathrm{OH}) \mathrm{CH}_{2} \mathrm{NH}\right]\right) \quad \mathbf{1 0},{ }^{[26]}$ and methyleneamine $\left(\psi\left[\mathrm{CH}_{2}^{2} \mathrm{NH}\right]\right) \mathbf{1 1}^{[2,3,27]}$ moieties (Fig. 2). Prior studies in our laboratories have mainly focused on the synthesis, conformational analysis, and biological applications of alkene peptide isosteres in $\delta$-amino acid building blocks $\mathbf{6}$ and the corresponding cyclopropane analogs 12 and 13 (Fig. 3). [28] The relatively rigid, trisubstituted $(E)$-alkenes $6(\psi[(E)$ $\mathrm{C}(\mathrm{R})=\mathrm{CH}]$ ) represent useful, conformationally preorganized structural mimetics and have been used as surrogates of hydrolytically labile amide bonds in a number of enzyme inhibitors. ${ }^{29]}$

The primary objective of the alkene peptide bond isostere strategy is the accurate mimicry of the geometry of the peptide bond, particularly its rigidity, bond angle, and length. We have constructed several analogs of the cyclodecapeptide gramicidin S (GS) in order to study the effects of specific amide bond replacements on the overall conformation and the biological activity of this antibiotic. ${ }^{[30]}$ We were able to demonstrate that key replacements of the natural peptide sequence at the D-Phe-Pro $\beta$-turn as well as the Leu-D-Phe $\beta$-sheet positions conserved the parent GS secondary structure as well as its biological effects. While trisubstituted $(E)$-alkenes, like many other amide bond substitutes, lack effective hydrogen bond donor and acceptor functions and do not provide for the large dipole moment of resonance stabilized amide groups, our trifluoromethylated alkene isosteres (vide infra) partly address this deficiency and more accurately mimic the dipole moment of the amide bond (3.6 D vs $2.3 \mathrm{D}$ for trifluoroalkene isostere). ${ }^{[28 \mathrm{c}]}$ However, alkenes can suffer from potential isomerization, oxidation, and general chemical lability. On the basis of the latter considerations, we have designed cy- 

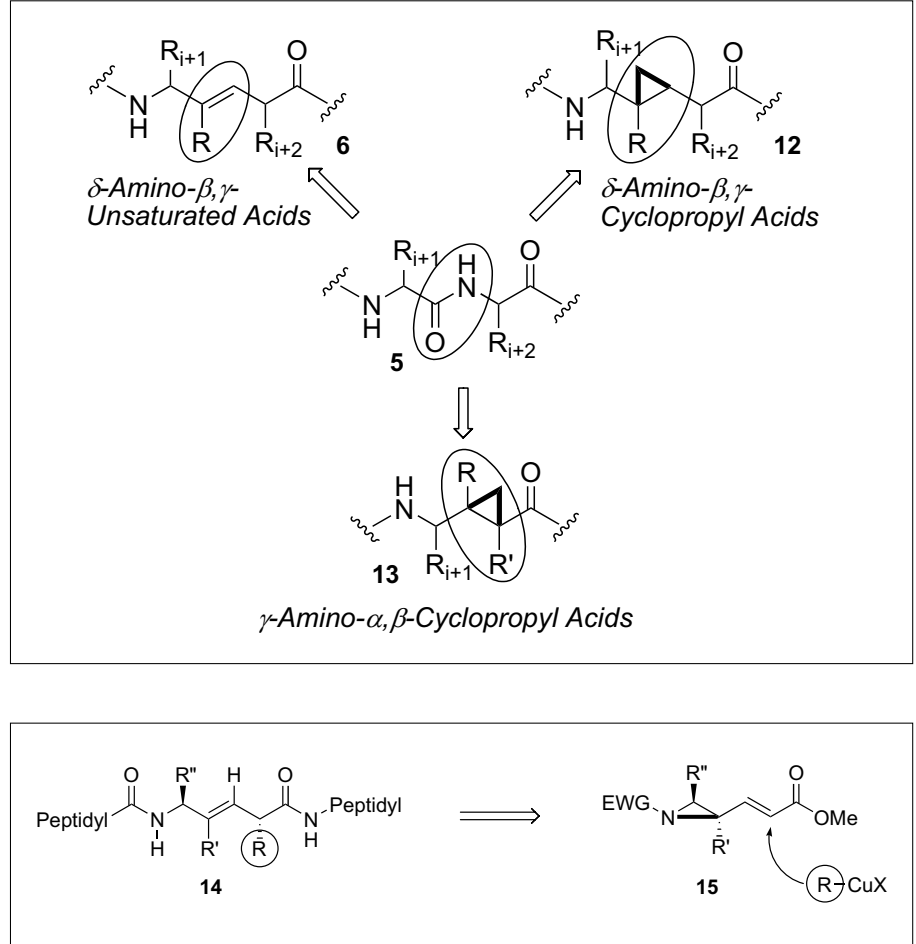

Scheme 1. Cuprate $\mathrm{S}_{\mathrm{N}} 2$ ' opening of alkenylaziridines can be used for alkene peptide isostere synthesis.

Fig. 4. Typical alkene based PLMs obtained from alkenylaziridine openings.

Diastereoselectivities ranged from 60 to $>98 \%$ and yields were 50-90\%.

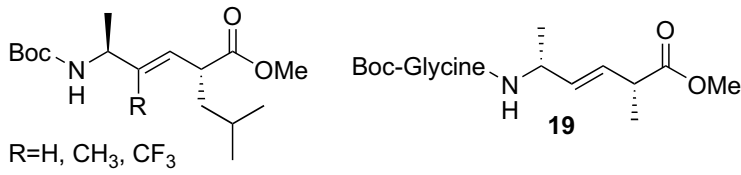

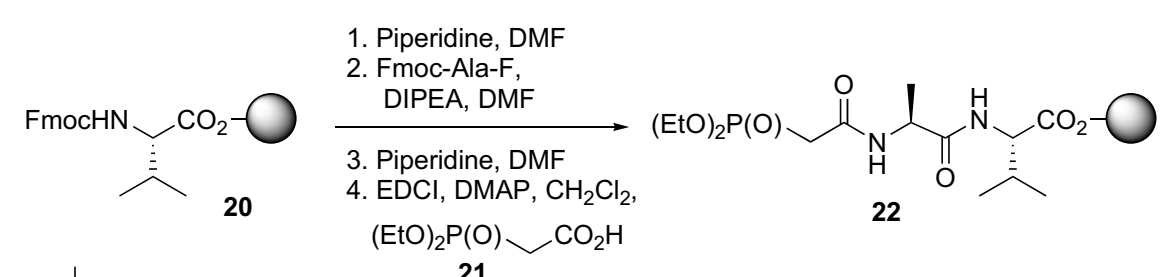

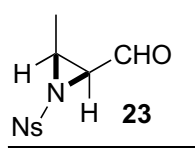

LHMDSA, THF, $-78 \rightarrow \mathrm{rt}$

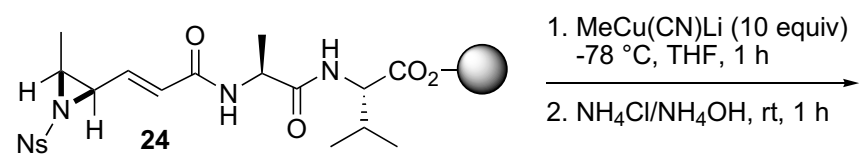

1. TFA, $\mathrm{CH}_{2} \mathrm{Cl}_{2}(1: 1)$

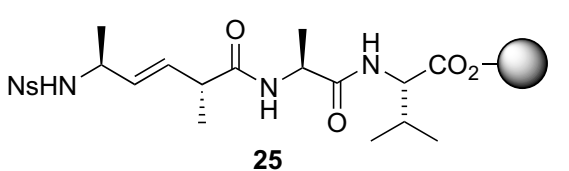

2. TMS-Cl, $\mathrm{MeOH}$<smiles>COC(=O)C(NC(=O)[C@H](C)NC(=O)[C@H](C)/C=C/[C@H](C)NN=N)C(C)C</smiles>

clopropane dipeptide isosteres ( $\psi[\mathrm{RCp}])$, which we expect to display increased stability compared with the corresponding (E)-alkene dipeptides.

\subsection{Synthesis of Alkene-based PLMs}

Our first attempts toward the stereoselective preparation of alkene peptide isosteres 14 focused on the $\mathrm{S}_{\mathrm{N}} 2$ - opening of alkenylaziridines $\mathbf{1 5}$ (Scheme 1). [28a,31] We envisioned that the broad functional group compatibility of cuprate reagents would allow the chemistry to tolerate the typical side chain as well as backbone functions of oligopeptides. Indeed, we were able to generate di- and tripeptide sequences, such as 16-19 in solution in high diastereomeric excess if strongly electron-withdrawing (EWG) $N$-activating groups were used (Fig. 4). An extension to solid phase peptide synthesis (SPPS) was also feasible with Wang-resin bound $N$-nosylated aziridines 24 (Scheme 2). $[28]$

While the alkenylaziridine opening and related allylic displacements allowed us to prepare conformationally rigidified, trisubstituted alkene peptide isosteres, including novel trifluoromethylalkenes, ${ }^{28 \mathrm{c}]}$ the synthetic pathway was too linear to allow a ready expansion to libraries of backbone modified isosteres. Fortunately, at this time, the scope of our zirconocene-zinc transmetalation methodology had been expanded to include the use of imine electrophiles, ${ }^{[32]}$ and the resulting synthetic sequence provided versatile access to the desired $\delta$-amino acid building blocks (Scheme 3).[22d,e] Hydrozirconation of alkynylstannane 27 followed by in situ transmetalation to dimethylzinc and 1,2-addition to imine $\mathbf{2 8}$ provided the allylic phosphinoylamide $\mathbf{2 9}$ in $62 \%$ yield as a 1.5:1 mixture of diastereomers. The stannyl group was exchanged with an iodide by electrophilic halogenation, and a Negishi coupling introduced the phenyl group at the alkene position in $\mathbf{3 0}$. This intermediate was readily converted to the tetrapeptide isostere 32. Analogous products could also be obtained directly from a Stille coupling of stannane 29 (Scheme 4). In this versatile conversion, aromatic and heteroaromatic substituents are introduced in moderate to high yields to give alkene isosteres $\mathbf{3 3}$.

The versatility of stannane $\mathbf{2 9}$ was further exploited by a stereoselective conversion to fluoroalkene 34 (Scheme 5). The introduction of the trifluoromethyl group, in contrast, was more challenging, requiring the conversion of iodide $\mathbf{3 5}$ to amide 36, followed by copper(I)thiophene carboxylate $(\mathrm{CuTc})$ catalyzed transfer of the trifluoromethyl group from methyl (fluorosulfonyl)difluoroacetate (37). [33] 


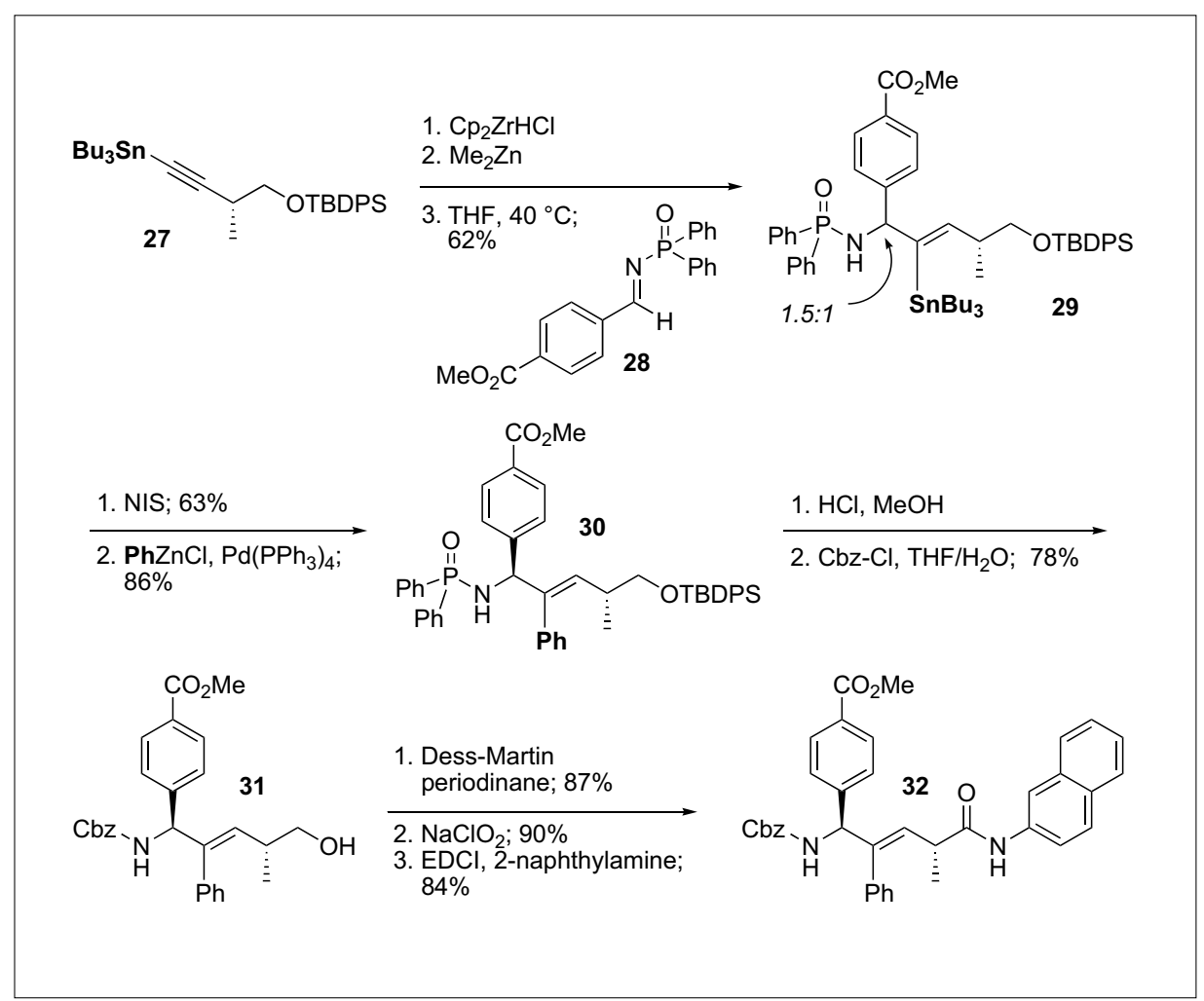

Scheme 3. Imine addition cascade followed by Negishi cross-coupling provides a convergent access to trisubstituted alkene peptide isosteres.

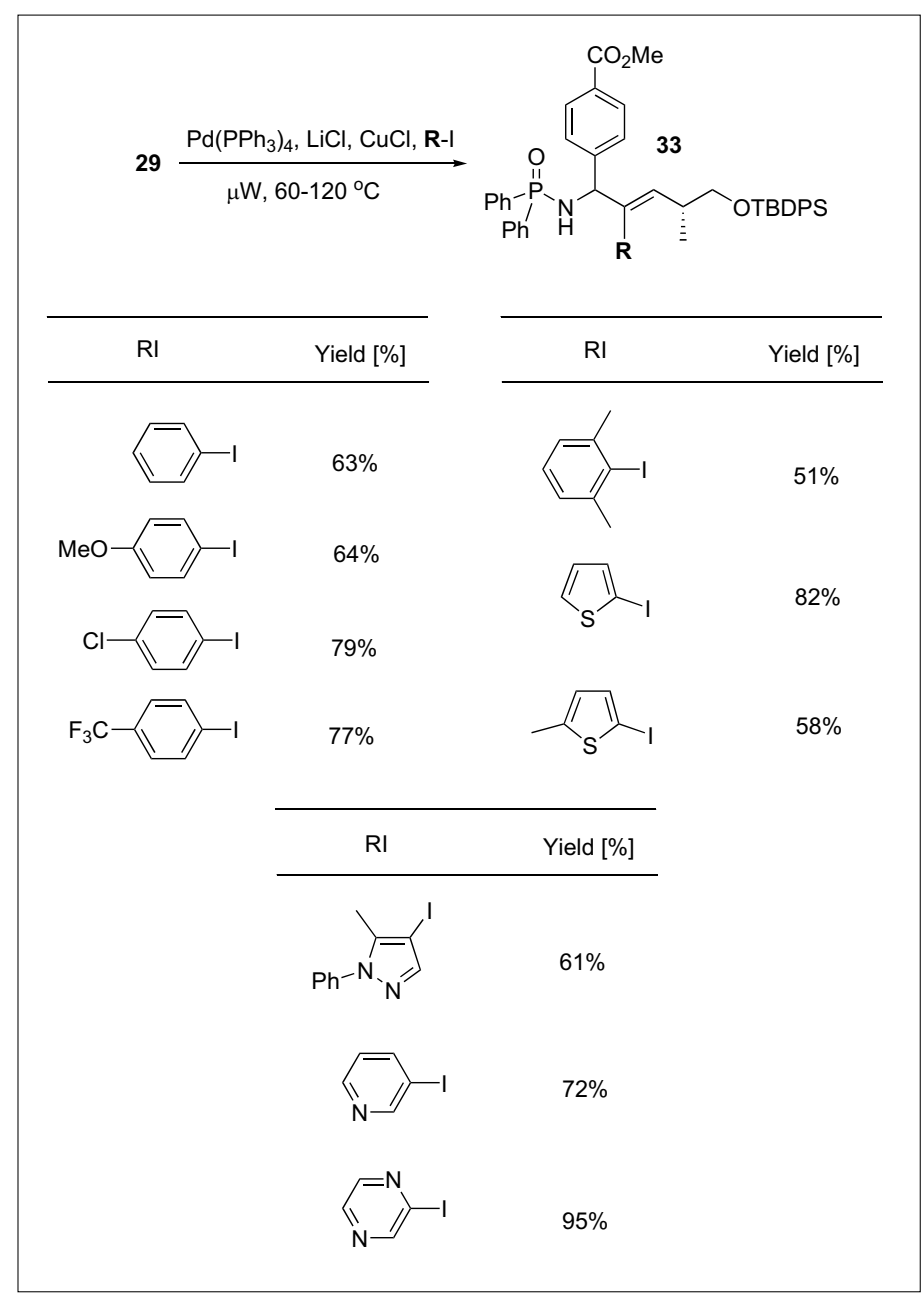

Scheme 4. Microwave-accelerated Stille coupling on stannane 29 leads to trisubstituted alkene isosteres $\mathbf{3 3}$.

\subsection{Synthesis of Cyclopropane- based PLMs}

A decisive advantage of the zirconocene-zinc-imine addition methodology over the earlier generation alkenylaziridine opening is represented by the opportunity to combine the addition reaction with an in situ Simmons-Smith cyclopropanation step, thus providing access to trisubstituted cyclopropane dipeptide isosteres $(\psi[\mathrm{RCp}])$ (Scheme 6). Hydrozirconation of alkyne 40 followed by in situ sequential addition of dimethylzinc, diphenylphosphinoylimine, and diiodomethane provided cyclopropane 41 as a mixture of diastereomers which were separated after deprotection and $\mathrm{N}$ Cbz protection. Alcohols $\mathbf{4 2}$ and $\mathbf{4 3}$ could be oxidized to the acid and coupled with amines to give backbone-cyclopropanated tetrapeptide mimetics $\mathbf{4 4}$ and $\mathbf{4 5}$, respectively. Alternatively, two-step oxidation of 43 and coupling with phenylalanine led to the chain-extended PLM 46.

In addition to the $\beta, \gamma$-cyclopropyl$\delta$-amino acids obtained as part of the synthetic sequence shown in Scheme 6, we were also interested in the access to $\alpha, \beta$-cyclopropyl- $\gamma$-amino acids 49 , which we considered isosteric to the vinylogous amino acids 48 (Fig. 5). A number of natural products, including the cyclotheonamides, feature the latter residues and have inspired synthetic as well as conformational studies. However, the chemistry of the corresponding cyclopropane derivatives has been surprisingly neglected. We chose the phenylglycine derivatives $\Delta \mathrm{Phg}$ (52), $\beta \mathrm{Me} \Delta \mathrm{Phg}(\mathbf{5 3})$, and $\alpha \mathrm{Me} \Delta \mathrm{Phg}(\mathbf{5 4})$ as representative examples that could be readily prepared by a multicomponent $\mathrm{Zr}$ $\mathrm{Zn}$ imine addition strategy (Fig. 6).

Due to the electron-withdrawing effects of the silyl ether oxygen, the cascade hydrozirconation-transmetalation-imine addition-Simmons Smith chemistry of propargyl ether $\mathbf{5 5}$ stopped at the alkene stage, i.e. the cyclopropanation did not proceed, and allylic amide $\mathbf{5 6}$ was isolated in $65 \%$ yield (Scheme 7). Accordingly, we hydrozirconated the homopropargylic ether 57, and with this substrate, the in situ Simmons-Smith cyclopropanation proceeded as expected to give the cyclopropylmethylamine 58 in $61 \%$ yield. Alcohol deprotection was followed by a Grieco elimination to give alkene 60, and ozonolysis in basic methanol led to $\Delta \mathrm{Phg}$ methyl ester 61 . A related sequence of transformations starting with the 2-butynol derivative led to the $\beta \mathrm{Me} \Delta \mathrm{Phg}$ building block, and a related strategy was also used in the preparation of $\alpha \mathrm{Me} \Delta \mathrm{Phg}$ derivative 67 (Scheme $8)$.

Zirconocene-catalyzed water accelerated carboalumination of $\mathbf{5 7}$, followed by imine addition in the microwave led to the trisubstituted alkene $\mathbf{6 2}$ in $85 \%$ yield. 


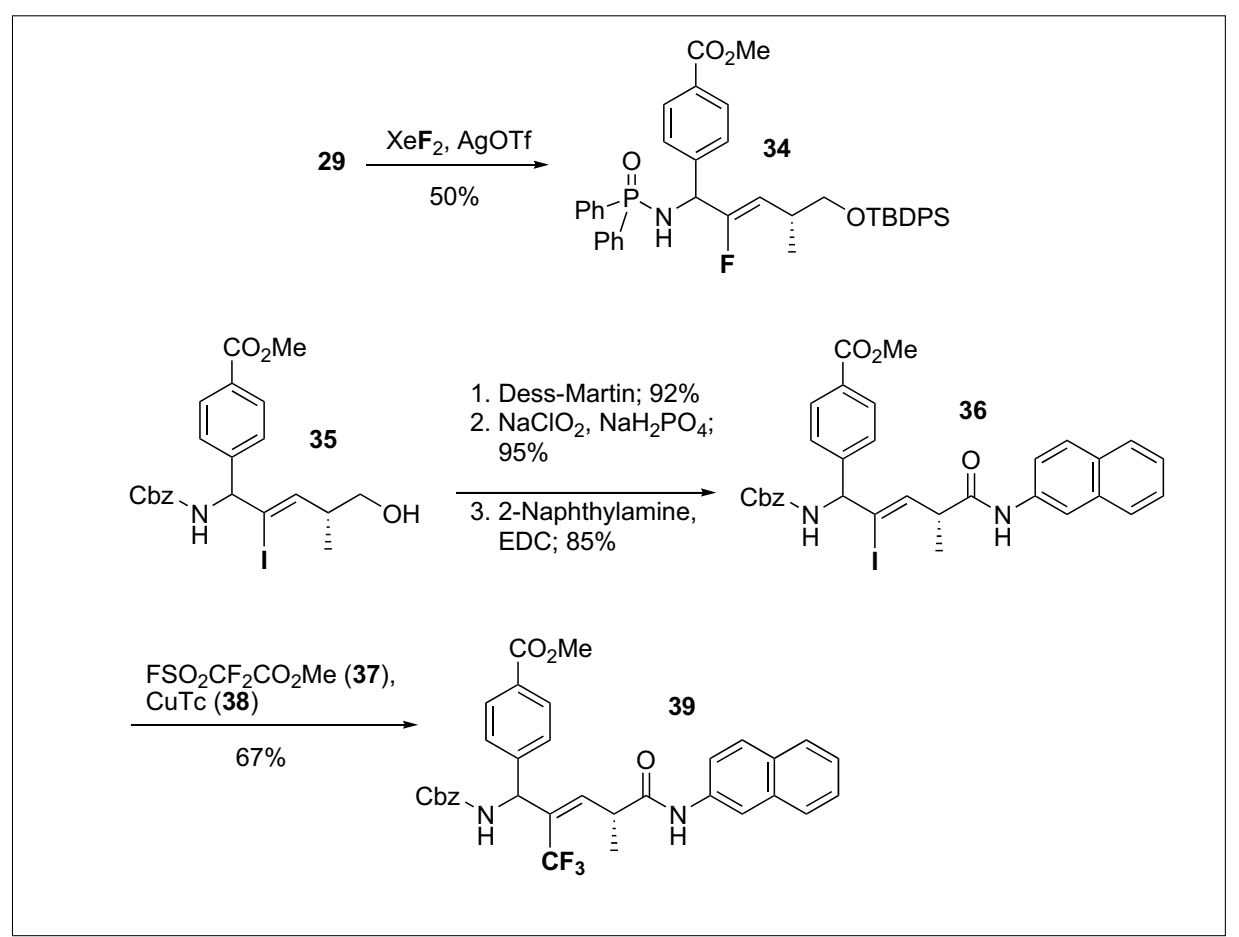

Scheme 5. Fluorination of vinyl stannane $\mathbf{2 9}$ and trifluoromethylation of vinyl iodide $\mathbf{3 6}$ provides fluoro and trifluoromethyl alkene amide bond isosteres.

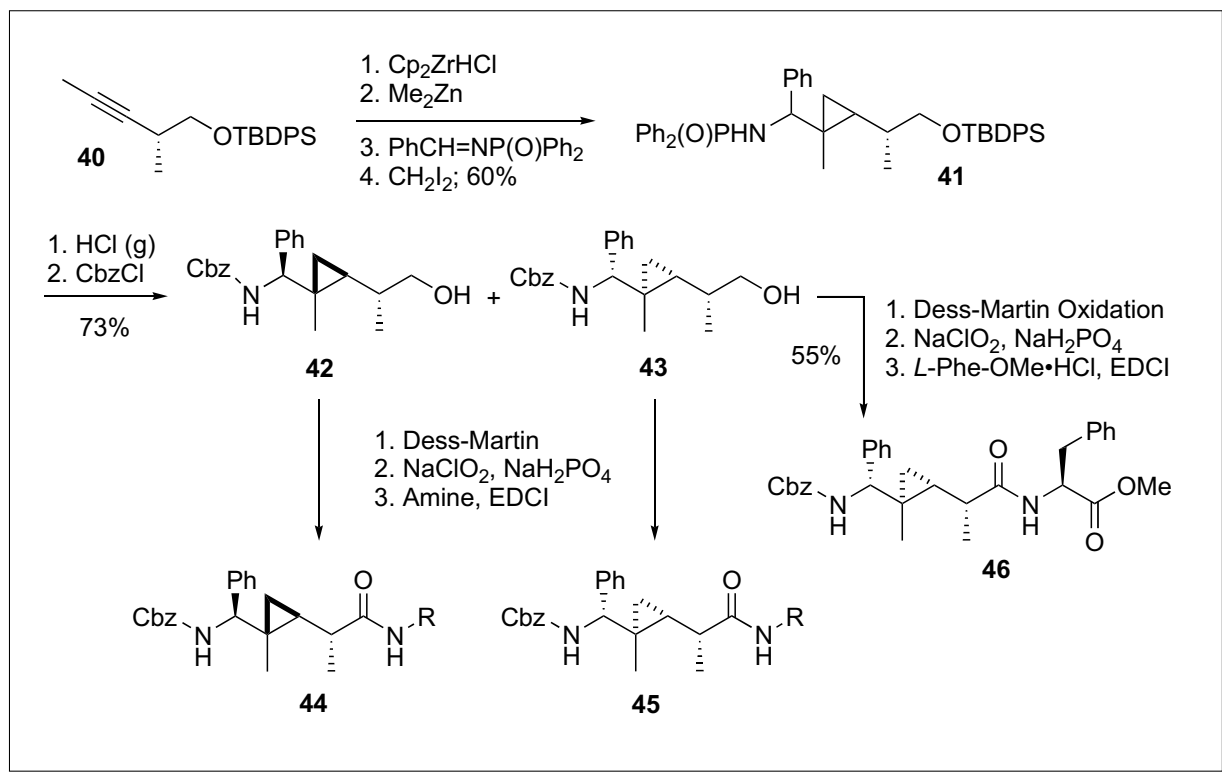

Scheme 6. Preparation of cyclopropane dipeptide isostere building blocks.
A subsequent cyclopropanation with the DME complex of bis(iodomethylene)zinc gave the syn-cyclopropylalkylamine 63 after deprotection of the silyl ether. Grieco elimination, ozonolysis, and protective group manipulations resulted in the desired $\alpha \mathrm{Me} \Delta \mathrm{Phg}$ segment 67.

Among the three $\alpha, \beta$-cyclopropyl$\gamma$-amino acids 52-54 shown in Fig. 6, the $\alpha \mathrm{Me} \Delta \mathrm{Phg}$ building block exerted the strongest conformational preorganization in oligomeric assemblies. The properties of this building block in amino acid-cyclopropane isostere hybrids were studied, among others, in PLMs 68 and 69 (Fig. 7). Interestingly, 69 adopts an extended backbone conformation in the solid state, crystallizing as an anti-parallel dimer. The dihedral angles at the backbone cyclopropane-extended amino acid residue are $>135^{\circ}$, as a consequence of minimizing allylic strain. This secondary structure preference is similar to that observed earlier by for vinylogous amino acids by Schreiber and co-workers. ${ }^{[34]}$ The geometric homology between naturally occurring vinylogous amino acids and novel backbone cyclopropane-extended residues such as $\alpha \mathrm{Me} \Delta \mathrm{Phg}$ bodes well for the use of the latter building blocks in the design of conformationally preorganized peptide mimetics. $\beta$-Sheets are important for protein-protein and protein-DNA interactions, and templates that induce these extended conformations are useful tools in medicinal and host-guest chemistry. ${ }^{[35]}$

\subsection{Synthesis and Secondary Structure Analysis of Gramicidin S Analogues with (E)-Alkene Peptide Isosteres}

Gramicidin S (GS; cyclo[(Val-OrnLeu-D-Phe-Pro) $\left.{ }_{2}\right]$ ), a cyclodecapeptide antibiotic agent isolated from Bacillus brevis, has a remarkable resistance to peptide-cleaving proteases. ${ }^{[36]}$ Its mode of action includes interaction with microbial membrane lipids, dissipation of the chemiosmotic potential and inhibition of respiratory enzymes. This biological function,

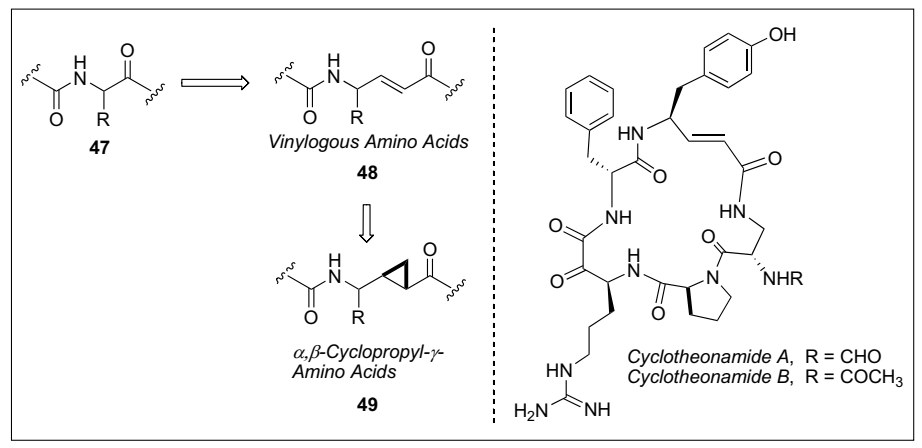

Fig. 5. $\alpha, \beta$-Cyclopropyl- $\gamma$-amino acids building blocks are related to vinylogous amino acids found in natural products.

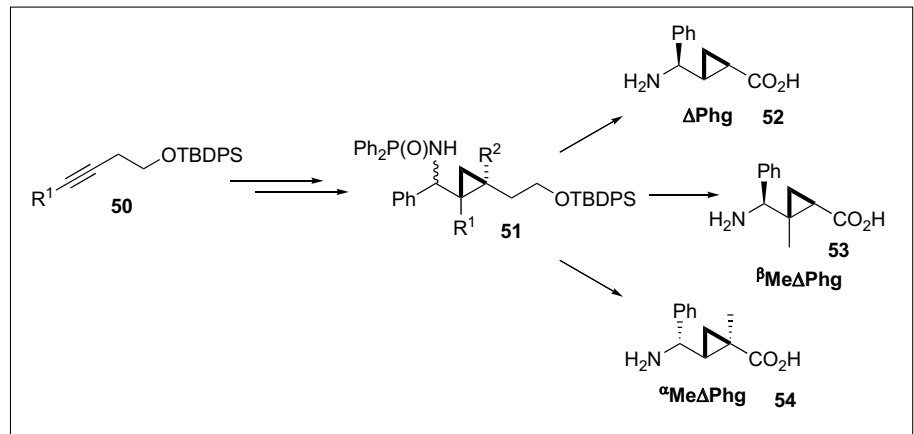

Fig. 6. First-generation phenylglycine-derived $\alpha, \beta$-cyclopropyl- $\gamma$-amino acids. 

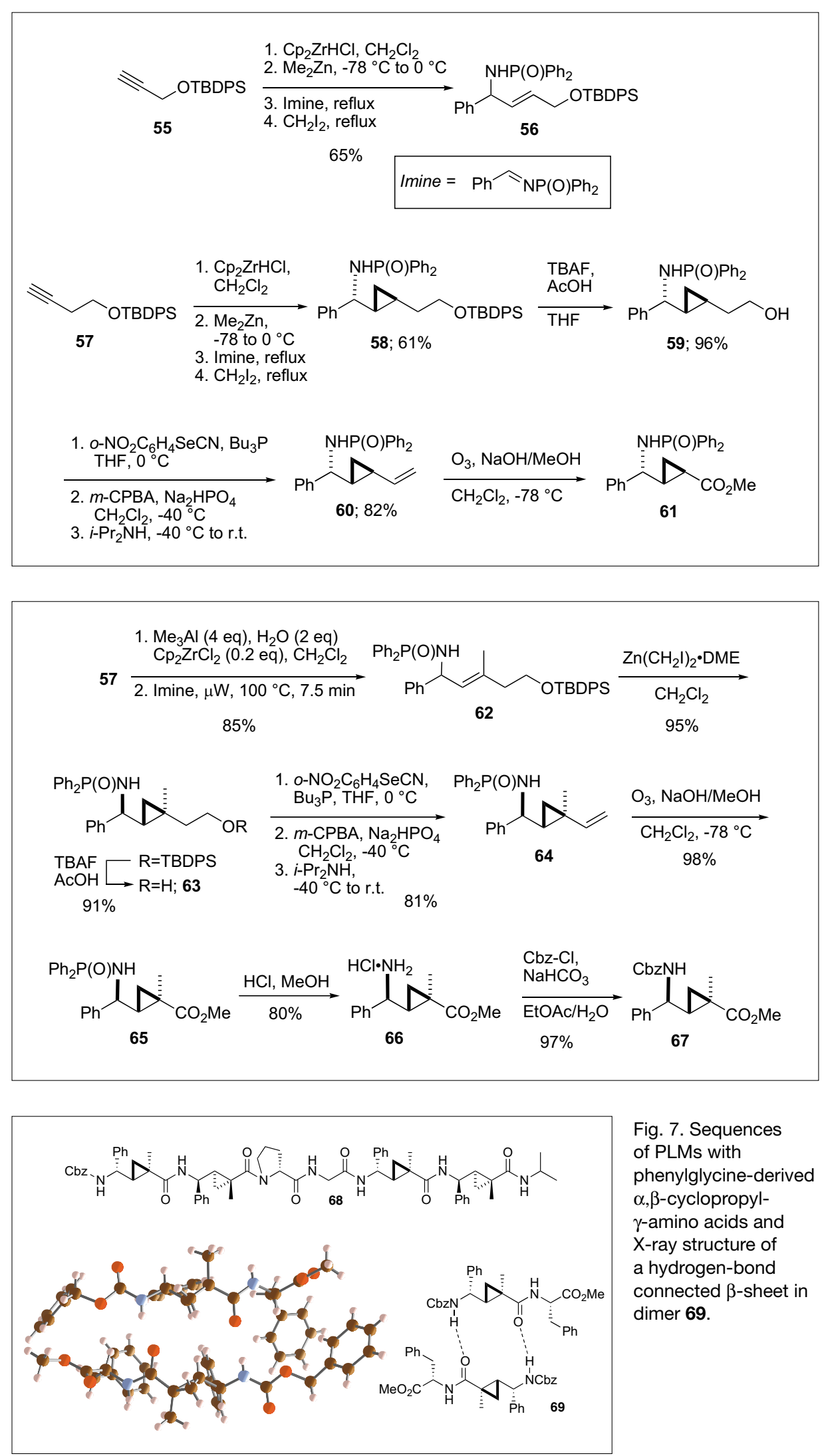

Fig. 7. Sequences of PLMs with phenylglycine-derived $\alpha, \beta$-cyclopropyl$\gamma$-amino acids and $X$-ray structure of a hydrogen-bond connected $\beta$-sheet in dimer 69.

including its hemolytic activity, has been closely correlated to its secondary structure, comprised of an amphipathic antiparallel $\beta$-sheet and two type II' $\beta$-turns. Replacement of the D-Phe-Pro sequence in GS has become a control experiment for the evaluation of the turn-inducing potential of many $\beta$-turn mimetics. ${ }^{[37]}$ Sur- prisingly, prior to our work, the effect of alkene peptide isosteres had not yet been evaluated on the GS scaffold. We therefore decided to explore key replacements of the natural peptide sequence at the LeuD-Phe $\beta$-turn as well as the D-Phe-Pro $\beta$ sheet positions in $\mathbf{7 0}$ and $\mathbf{7 1}$, respectively (Fig. 8).
Scheme 7. Preparation of the disubstituted cyclopropane-containing $\Delta \mathrm{Phg}$ building block 61.

Scheme 8. Preparation of the trisubstituted cyclopropane-containing $\alpha \mathrm{Me} \Delta \mathrm{Phg} 67$.

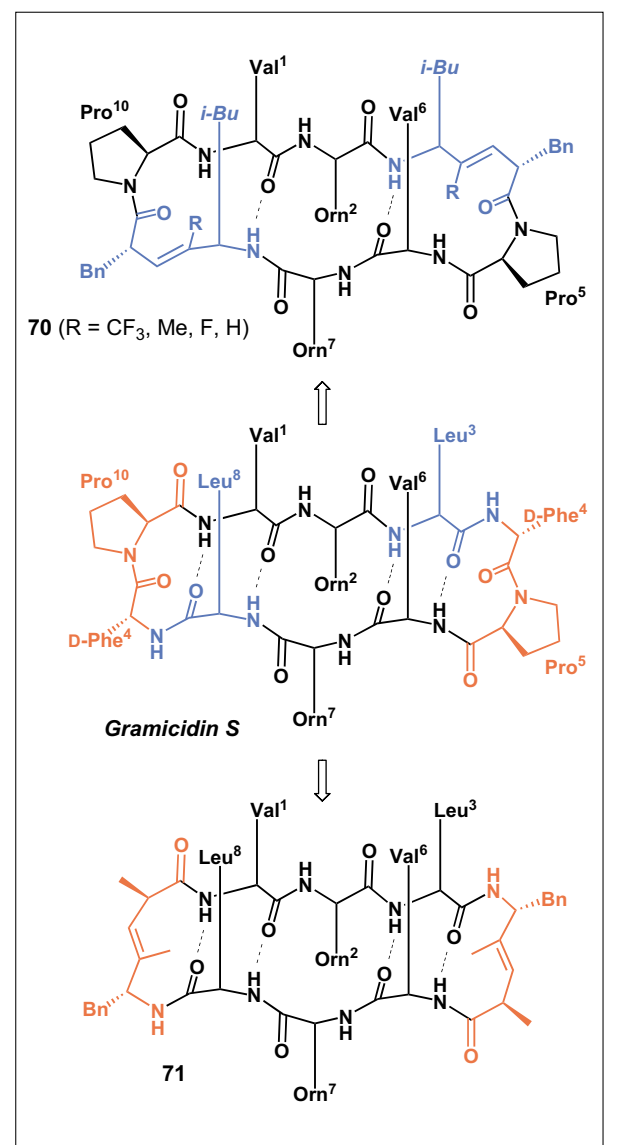

Fig. 8. Gramicidin $\mathrm{S}$ analogs with selective alkene peptide bond isostere replacements. 


$$
\text { 年 }
$$
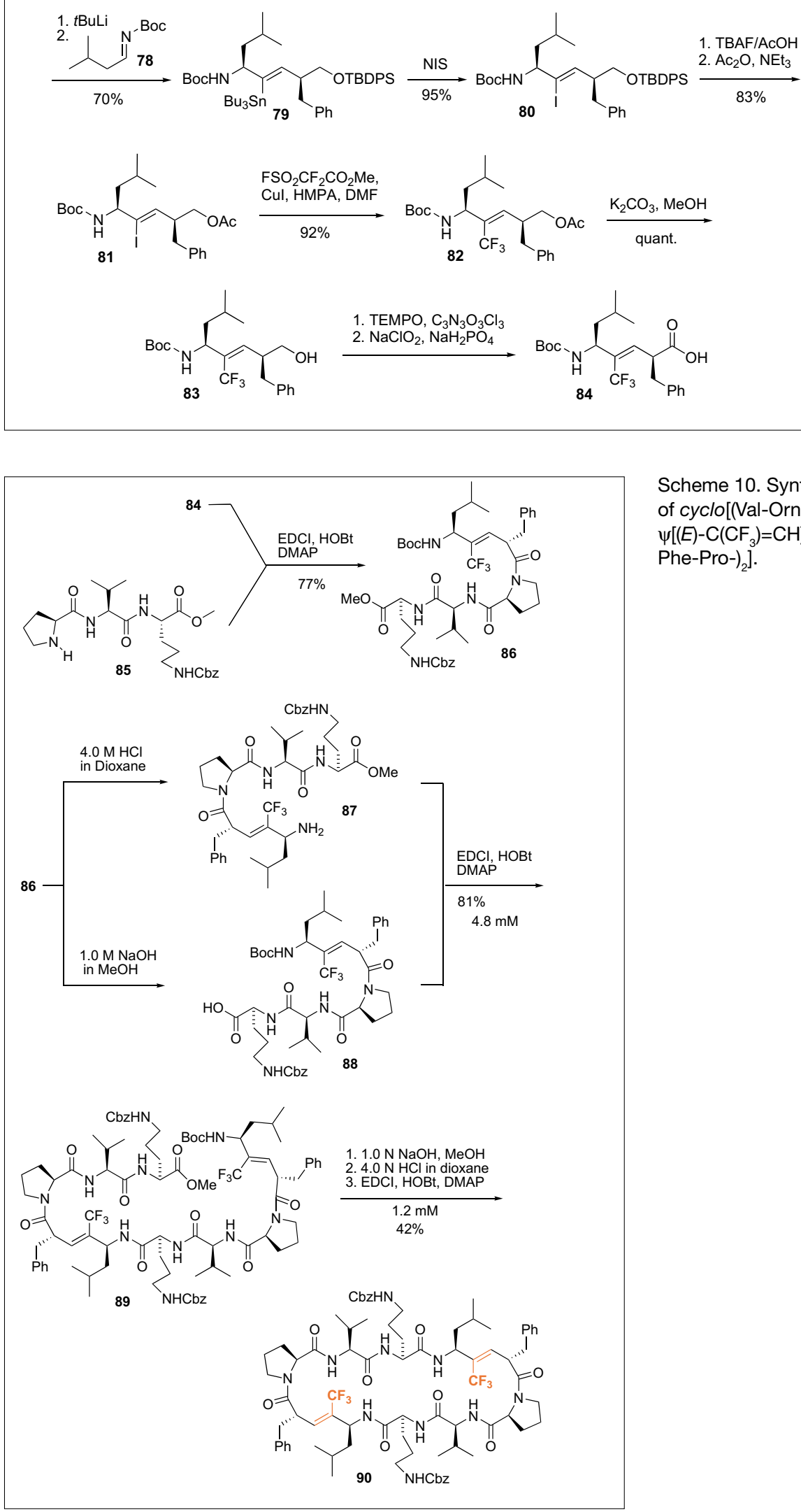

Scheme 9. Preparation of the L-Leu( $\psi[(E)-$ $\left.\left.\mathrm{C}\left(\mathrm{CF}_{3}\right)=\mathrm{CH}\right]\right)$-D-Phe segment.

Our first concern in the preparation of these target hybrid structures was the development of a scalable route for the L-Leu $(\psi[(E)-\mathrm{C}(\mathrm{R})=\mathrm{CH}])-\mathrm{D}-\mathrm{Phe}$ segment (Scheme 9). The chiral alcohol $\mathbf{7 2}$ was obtained by acylation of the $(R)$-benzyloxazolidine with hydrocinnamoyl chloride, followed by alkylation of the titanium(IV) enolate with BOM-chloride and $\mathrm{LiBH}_{4}$ reduction. $O$-Silylation of $\mathbf{7 2}$ and hydrogenolysis yielded primary alcohol 74, which was oxidized to the aldehyde and subjected to a Corey-Fuchs alkynylation sequence. Trapping with tributylstannylchloride gave stannylalkyne 76 in high yield. Hydrozirconation and selective iodination of the $\mathrm{C}-\mathrm{Zr}$ bond in the bimetallic intermediate provided vinyl iodide 77 . Halogen-lithium exchange followed by imine addition proceeded smoothly, and the vinyl stannane 79 was isolated in $70 \%$ yield. For the introduction of the trifluoromethyl group, stannane moiety was converted to iodide 80, the silyl ether was switched to the acetate function, and ester $\mathbf{8 1}$ was subjected to methyl (fluorosulfonyl)difluoroacetate and copper iodide. The desired trisubstituted alkene peptide isostere $\mathbf{8 2}$ was isolated in excellent yield and readily converted to acid 84 by sequential oxidation with catalytic TEMPO and cyanuric chloride, followed by buffered sodium chlorite.

Segment condensation for decapeptide assembly was initiated by coupling of acid 84 with amine 85 in the presence of EDCI and HOBt (Scheme 10). Attempted cyclodimerization of the resulting pentapeptide 86, subsequent to deprotection of both the $N$-terminal Boc group and the $C$-terminal ester, only led to the undesired cyclomonomer. Accordingly, 86 was separately converted to amine $\mathbf{8 7}$ and acid $\mathbf{8 8}$, and the secopeptide $\mathbf{8 9}$ was prepared in $81 \%$ yield in a $5 \mathrm{mM}$ coupling solution. After $N$ - and $C$-terminal deprotection, macrolactamization was accomplished in a $1 \mathrm{mM}$ solution in $42 \%$ yield with a carbodiimide/HOBt cocktail. The GS analog cyclo[(Val-OrnLeu- $\psi\left[(E)-\mathrm{C}\left(\mathrm{CF}_{3}\right)=\mathrm{CH}\right]-\mathrm{D}-$ Phe-Pro- $\left.)_{2}\right]$ (90) was analyzed by solution NMR and solid state X-ray, and found to have a $\beta$ pleated sheet backbone conformation homologous to GS (Fig. 9). The reverse turn conformation was only slightly altered by the presence of the $\mathrm{CF}_{3}$-alkene in place of the amide function, even though the former did not participate in the intramolecular $\mathrm{H}$ bond, thus confirming the successful functional mimicry. Further confirmation of the functional mimicry between the side-chain deprotected derivative of $\mathbf{9 0}$ and the natural 


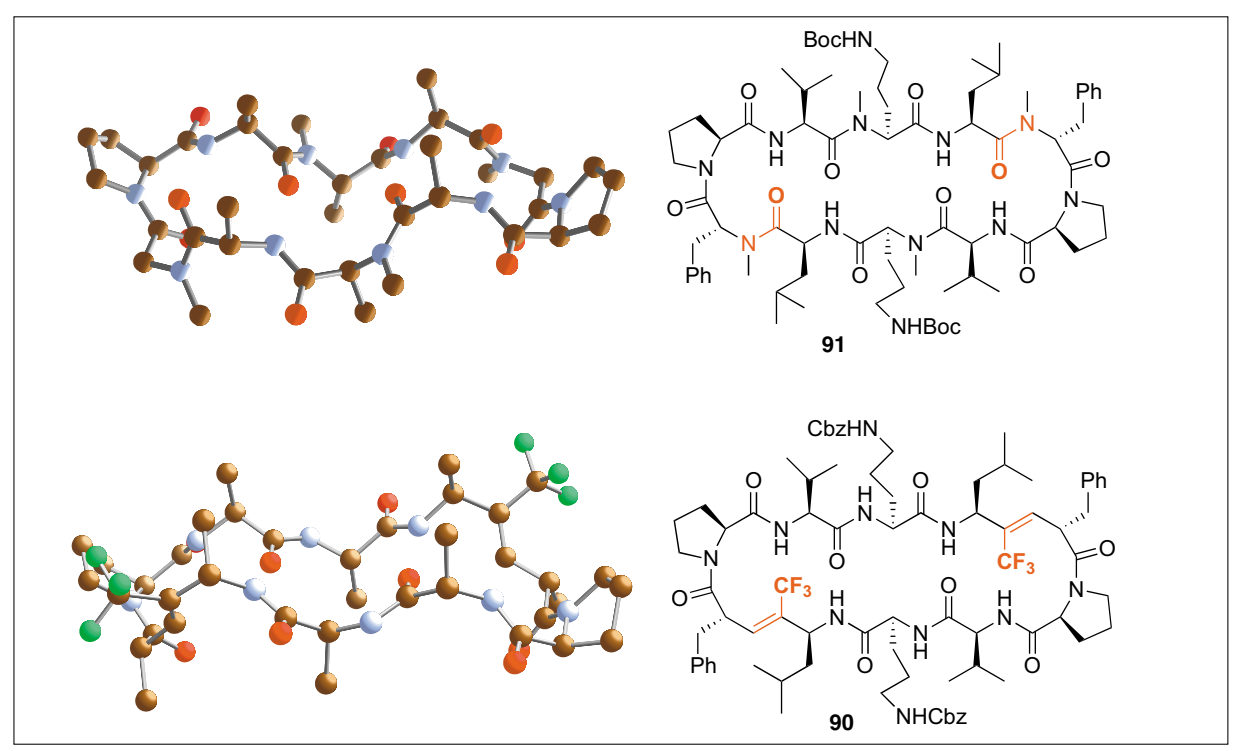

Fig. 9. Backbone comparisons based on x-ray structure analyses. Top: Gramicidin S, obtained as the ornithine Boc-protected, partially $N$-methylated derivative 91 ; bottom: bis-trifluoroalkene analog 90 . Only the backbone carbons and C $\beta$ 's of flexible side chains are shown.

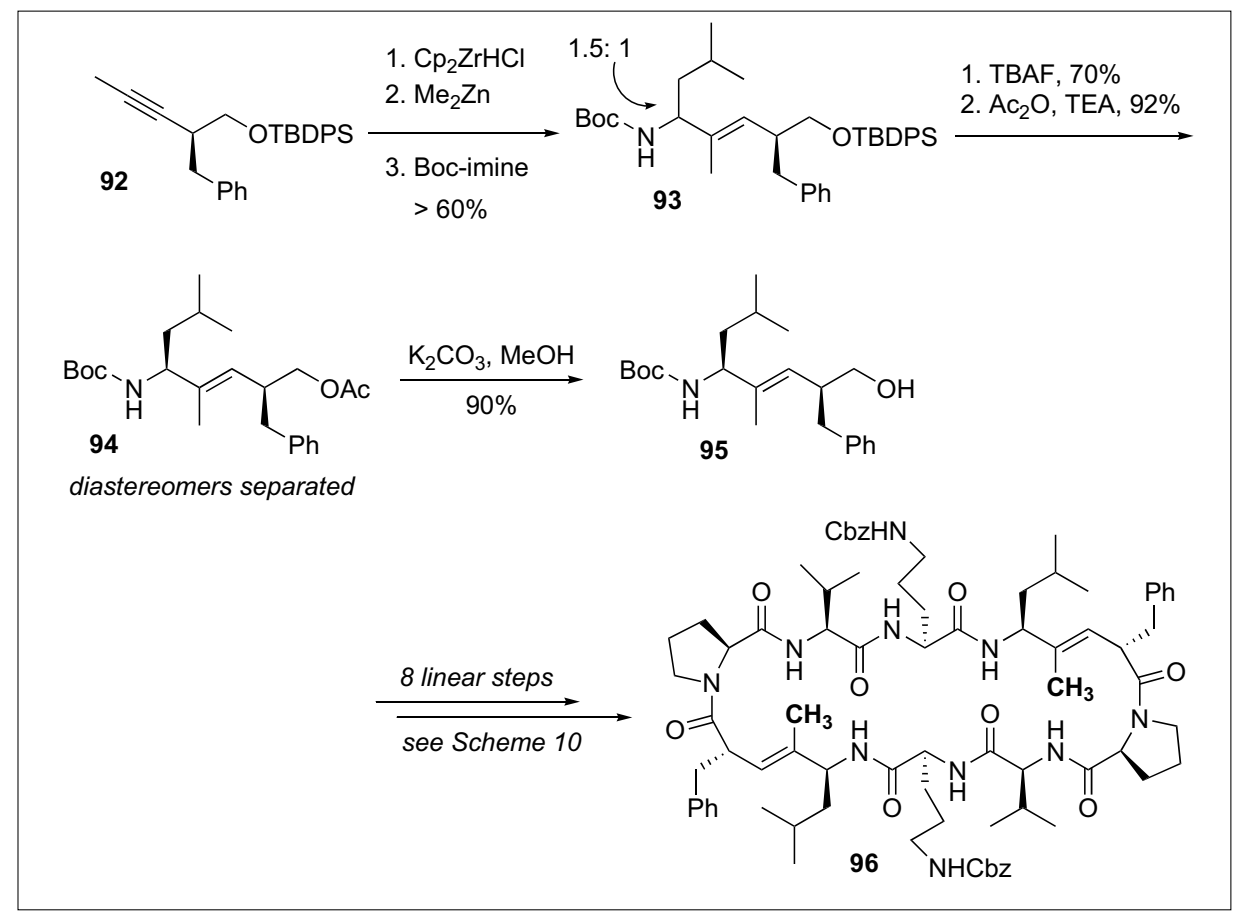

Scheme 11. Synthesis of cyclo[(Val-Orn-Leu- $\left.\left.\psi\left[(E)-\mathrm{C}\left(\mathrm{CH}_{3}\right)=\mathrm{CH}\right]-\mathrm{D}-\mathrm{Phe}-\mathrm{Pro}-\right)_{2}\right]$.

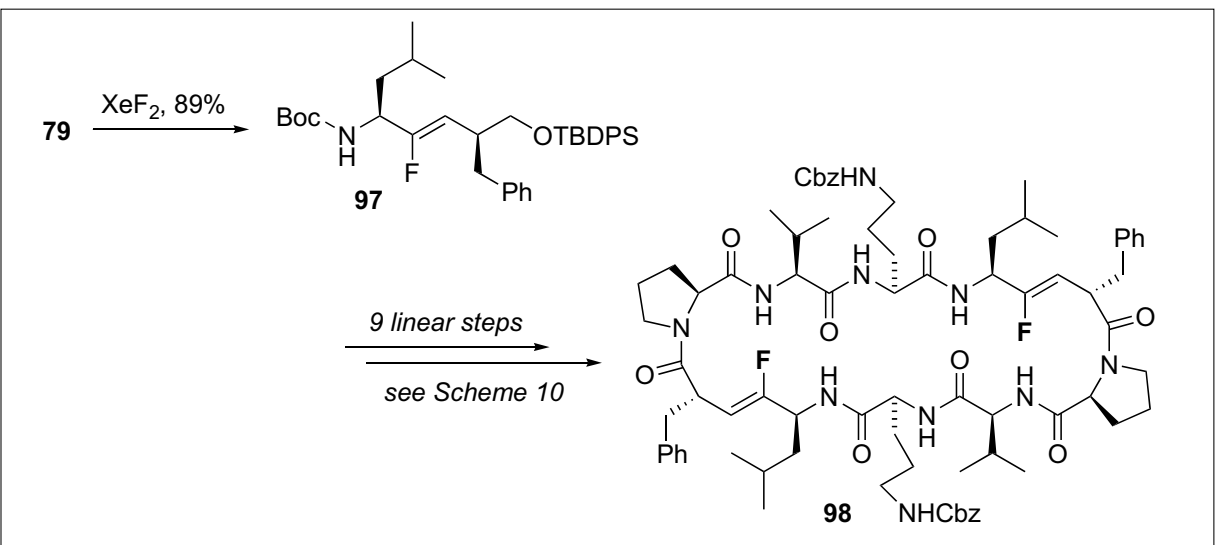

Scheme 12. Synthesis of $c y c / o\left[(V a l-O r n-L e u-\psi[(Z)-C(F)=C H]-D-P h e-P r o-)_{2}\right]$. product GS was obtained by a biological screen, where both compounds showed MICs of $5-15 \mu \mathrm{g} / \mathrm{mL}$ against $B$. subtilis.

The preparation of methyl-, fluoro-, and hydrogen-substituted alkene isosteres of GS was accomplished using a sequence similar to that used for the trifluoromethyl derivative 90. Hydrozirconation of alkyne 92 followed by transmetalation and imine addition resulted in the usual mixture of allylic amides 93, which were separated by chromatography on $\mathrm{SiO}_{2}$ after desilylation and acetylation to give the major diastereomer 94 (Scheme 11). After saponification, alcohol 95 was converted in eight linear steps to side-chain protected cyclo $\left[\left(\right.\right.$ Val-Orn-Leu- $\psi\left[(E)-\mathrm{C}\left(\mathrm{CH}_{3}\right)=\mathrm{CH}\right]-$ D-Phe-Pro- $\left.)_{2}\right]$ (96). The route to GS analog cyclo $[($ Val-Orn-Leu- $\psi[(Z)-\mathrm{C}(\mathrm{F})=\mathrm{CH}]-\mathrm{D}-$ Phe-Pro- $)_{2}$ ] was similarly straightforward with our methodology. Treatment of vinyl stannane 79 with xenon difluoride provided fluoroalkene $\mathbf{9 7}$ in excellent yield, and subsequent conversions to target compound 98 proceeded uneventfully in nine linear steps (Scheme 12) according to the stepwise coupling procedure shown in Scheme 10.

In addition, we also prepared the disubstituted alkene isostere cyclo[(Val-OrnLeu- $\psi[(E)-\mathrm{CH}=\mathrm{CH}]-\mathrm{D}-$ Phe-Pro- $\left.)_{2}\right]$ starting with terminal alkyne 99 (Scheme 13). The multi-component addition product 100 was isolated in high yield $(97 \%)$. After desilylation with TBAF and acetylation, the diastereomeric products 102 and 103 were separated by chromatography on $\mathrm{SiO}_{2}$. The assignment of the relative configuration of these compounds was based on the X-ray structure analysis of $\mathbf{1 0 2}$. The desired diastereomer 103 was quantitatively deacetylated with $\mathrm{K}_{2} \mathrm{CO}_{3}$ in $\mathrm{MeOH}$ and carried forward for the preparation of the corresponding disubstituted alkene peptide isostere segment 105 by a two-step oxidation with Dess-Martin periodinane, followed by $\mathrm{Na}$ $\mathrm{ClO}_{2}$. Further coupling steps followed the route shown earlier, and provided the cyclic PLM 106 in good overall yield.

We have previously postulated that trisubstituted $(E)$-alkene dipeptide isosteres are conformationally preorganized into $\beta$ turns, and that a $\mathrm{CF}_{3}$-substituted $(E)$-alkene $(\mu=2.3 \mathrm{D})$ would allow for an improved mimicry of the electrostatic potential surface of the parent amide bond $(\mu=3.6$ D). ${ }^{[28]}$ In addition to solid state structures, we also compared the solution conformations of GS and analogs 90, 96, 98, and 106 by circular dichroism in order to address this hypothesis (Fig. 10). The standard, bis-Cbz-protected GS, had a deep negative trough in the region of $205-210 \mathrm{~nm}$ along with a shoulder at $\sim 220 \mathrm{~nm}$, which can be explained by a combination of a type II' $\beta$-turn and an antiparallel $\beta$-sheet conformation. ${ }^{[38]}$ In comparison, the spectral 


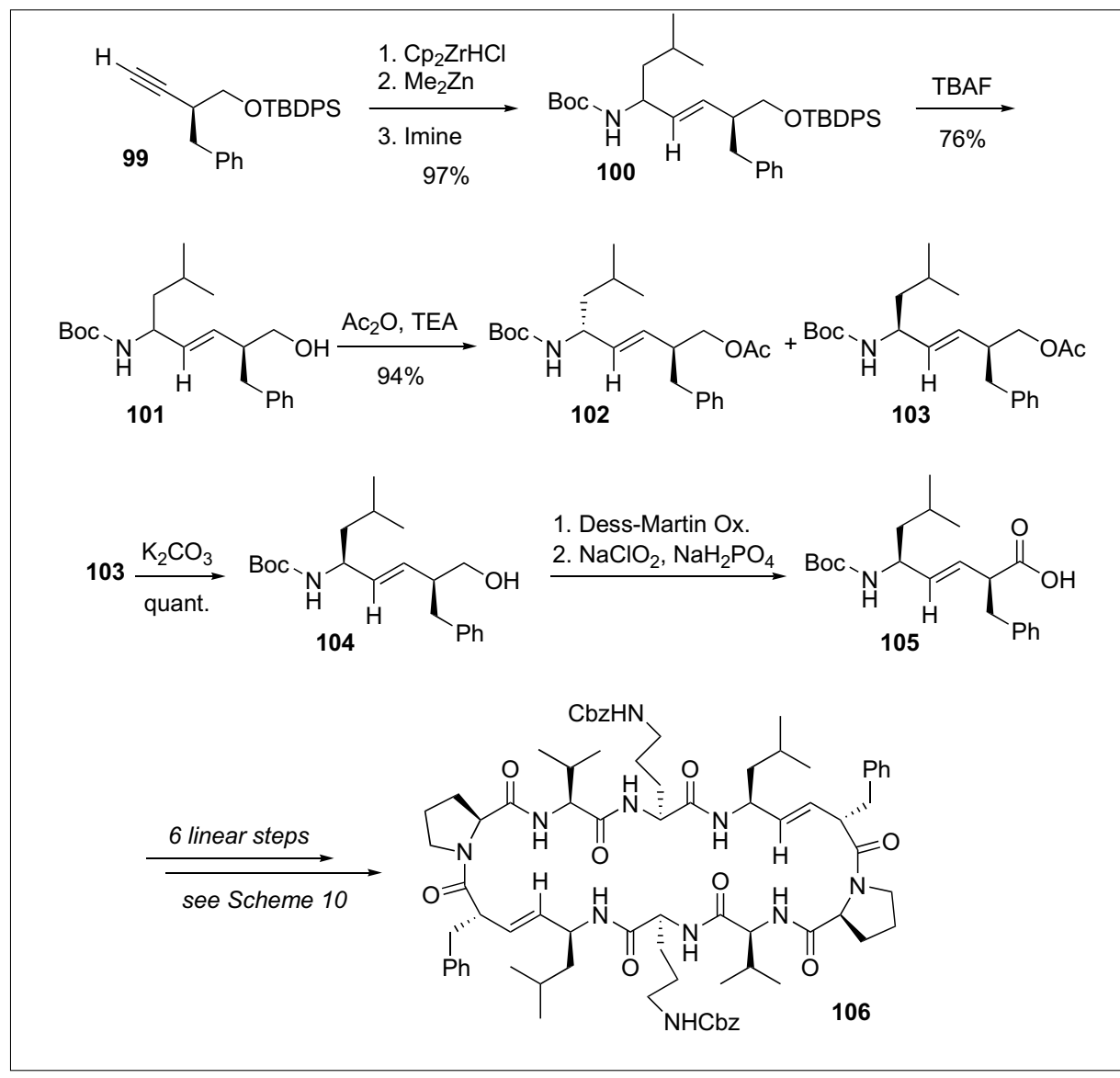

Scheme 13. Synthesis of the GS analog cyclo[(Val-Orn-Leu- $\left.\psi[(E)-\mathrm{CH}=\mathrm{CH}]-\mathrm{D}-\mathrm{Phe}-\mathrm{Pro}-)_{2}\right]$.

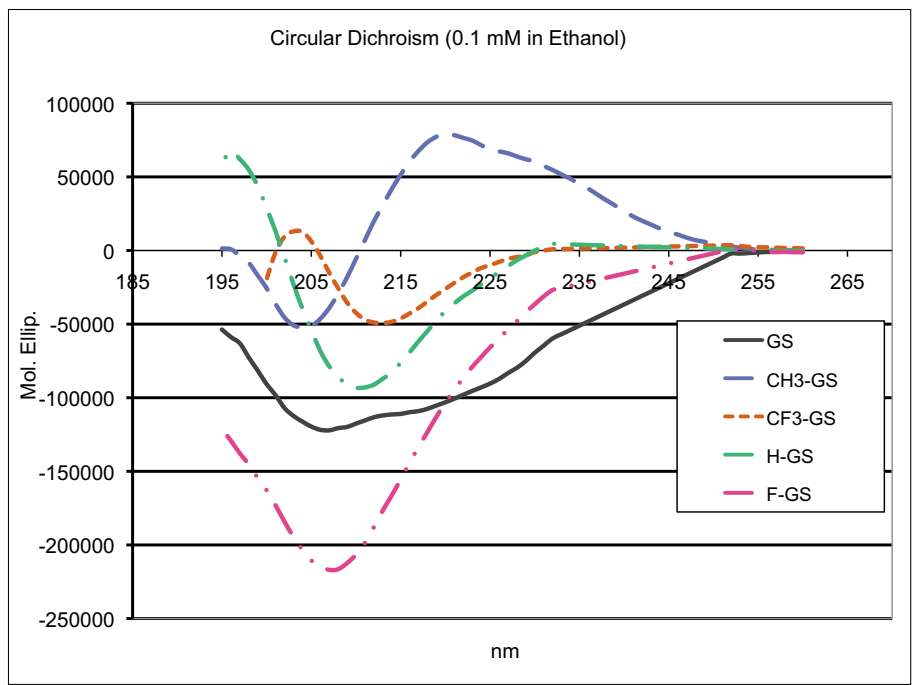

Fig. 10. Circular dichroism spectra for GS and analogs 90 (CF3-GS), 96 (CH3GS), 98 (F-GS), and 106 (H-GS).

shapes of the two GS analogues 90 and 96 were quite different. The methyl isomer 96 showed a negative trough in the region of 200-210 $\mathrm{nm}$ and a large positive trough in the region of $215-225 \mathrm{~nm}$, which indicated that 96 is likely to assume a rather flexible peptide conformation (much like a random coil). The trifluoromethyl isomer 90 displayed a negative trough in the region between $210-220 \mathrm{~nm}$, which indicated a dominant $\beta$-sheet conformation. Since the two carbonyl groups of the leucine residues, which contribute to the formation of the $\beta$-turns, were replaced with $\mathrm{C}-\mathrm{CF}_{3}$ moieties in 90, the $\beta$-sheet is nonetheless maintained by a movement of the two valine amides toward the inside of the ring and the formation of two pseudo $\beta$-turns. These two pseudo $\beta$-turns along with the two existing interstrand hydrogen bonds between $\mathrm{N}-\mathrm{H}$ (leucine) and $\mathrm{C}=\mathrm{O}$ (valine), confirmed in the X-ray analysis, induce a pseudo $\beta$-sheet formation in $\mathbf{9 0}$. This conformational analysis is further supported by NOE and variable temperature NMR experiments (not shown).
The CD spectrum of the disubstituted alkenes 106 and fluoroalkene 98 showed a similar negative trough in the region of 205-215 nm, indicative of a $\beta$-sheet conformation. Furthermore, the signal intensity order of the trough was $\mathbf{9 8}>\mathbf{1 0 6}>\mathbf{9 0}$, which might reflect the degree of backbone similarity to a GS-like structure. In our working hypothesis, the circular dichroism data indicate that $\mathbf{9 0}$ is superior to 96 and 98 is superior to $\mathbf{1 0 6}$ when considering electronic peptide bond mimicry. When considering the size effect at the alkene moiety and its perturbation of backbone conformation, the fluoroalkene 98 becomes a more effective mimic of GS than the trifluoromethylalkene $\mathbf{9 0}$, and the disubstituted alkene $\mathbf{1 0 6}$ is superior to trisubstituted alkene 96. Overall, it appears that for these cyclic PLMs, the size effect plays a more important role than the electronic properties of the backbone amide replacement.

In GS analogues 90, 96, 98, and 106, the carbonyl groups pointing toward the inside of the macrocycle and participating in the intramolecular hydrogen bonding network were replaced with isosteric alkenes. We were also interested in evaluating the replacement of amide bonds within the $\beta$-turn structure that did not participate in intramolecular hydrogen bonding, i.e. analog 71. Our earlier methodology was not well suited for the preparation of proline-based alkene peptide isosteres; however, in view of the conformational properties of a trisubstituted alkene, we hypothesized that a methyl side chain at $\mathrm{C} \alpha$ would be sufficient to mimic the turn-inducing effects of the imino acid. Furthermore, due to the potentially facile imine-enamine tautomerization of phenylacetaldimines, the sulfinyl adduct ${ }^{[39]} \mathbf{1 0 8}$ was employed as the imine precursor in the addition reaction of hydrozirconated-transmetalated alkyne $\mathbf{1 0 7}$ (Scheme 14).

Deprotection of the BDPS group with TBAF provided the primary alcohol $\mathbf{1 1 0}$ in $47 \%$ yield. The mixture of diastereomers generated in the imine addition step was subsequently separated at the stage of valine conjugate 111 via preparative $\mathrm{C}_{18}$ reverse phase HPLC. EDCI/ HOBt-mediated coupling of dipeptide $\mathrm{H}$ Orn(Cbz)-Leu-OMe afforded the linear pentapeptide analog $\mathbf{1 1 2}$ in $96 \%$ yield. We initially envisioned a one-pot dimerization-cyclization of 112, however, this approach resulted exclusively in formation of cyclized pentapeptide analog, similar to our earlier failed attempt with the trifluoromethylalkene 86. Gratifyingly, the stepwise deprotection of $\mathbf{1 1 2}$ and segment coupling proceeded smoothly to afford $\mathbf{1 1 5}$ in high yield (Scheme 15). Saponification of $\mathbf{1 1 5}$ and sequential re- 


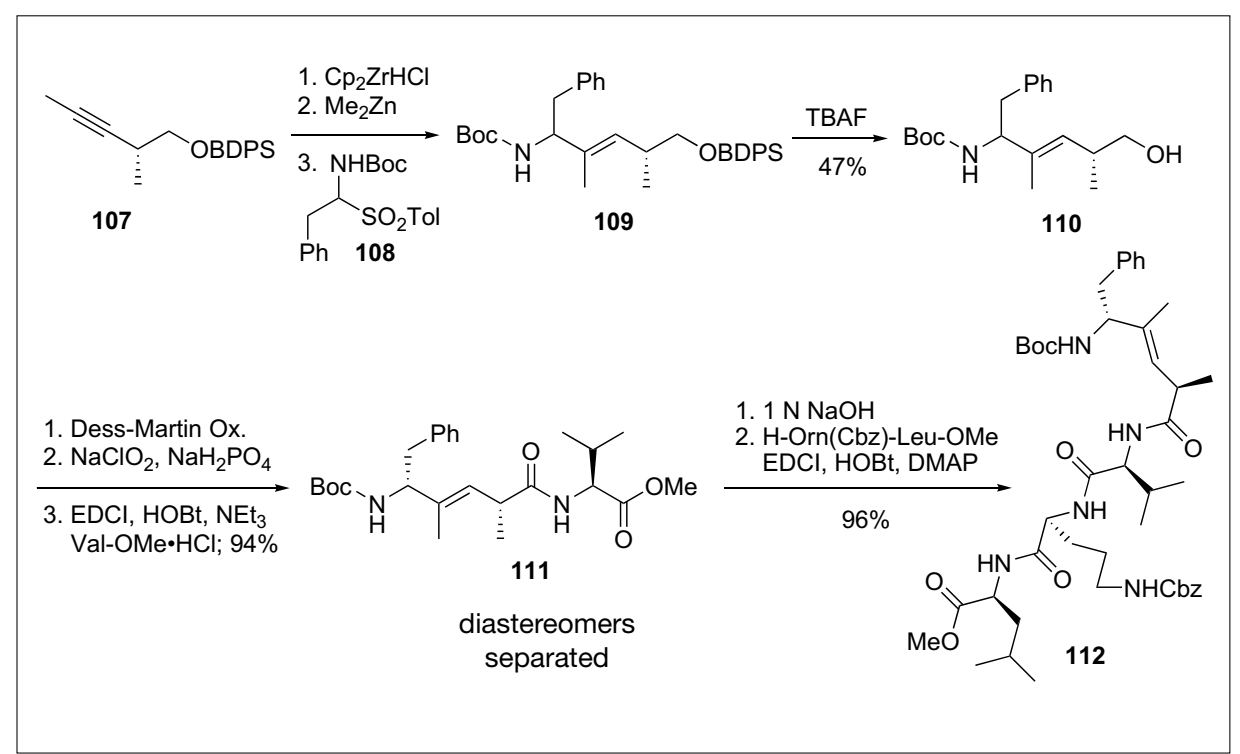

Scheme 14. Synthesis of a GS segment 112 with a trisubstituted alkene amide bond replacement at $D$-Phe-Pro.

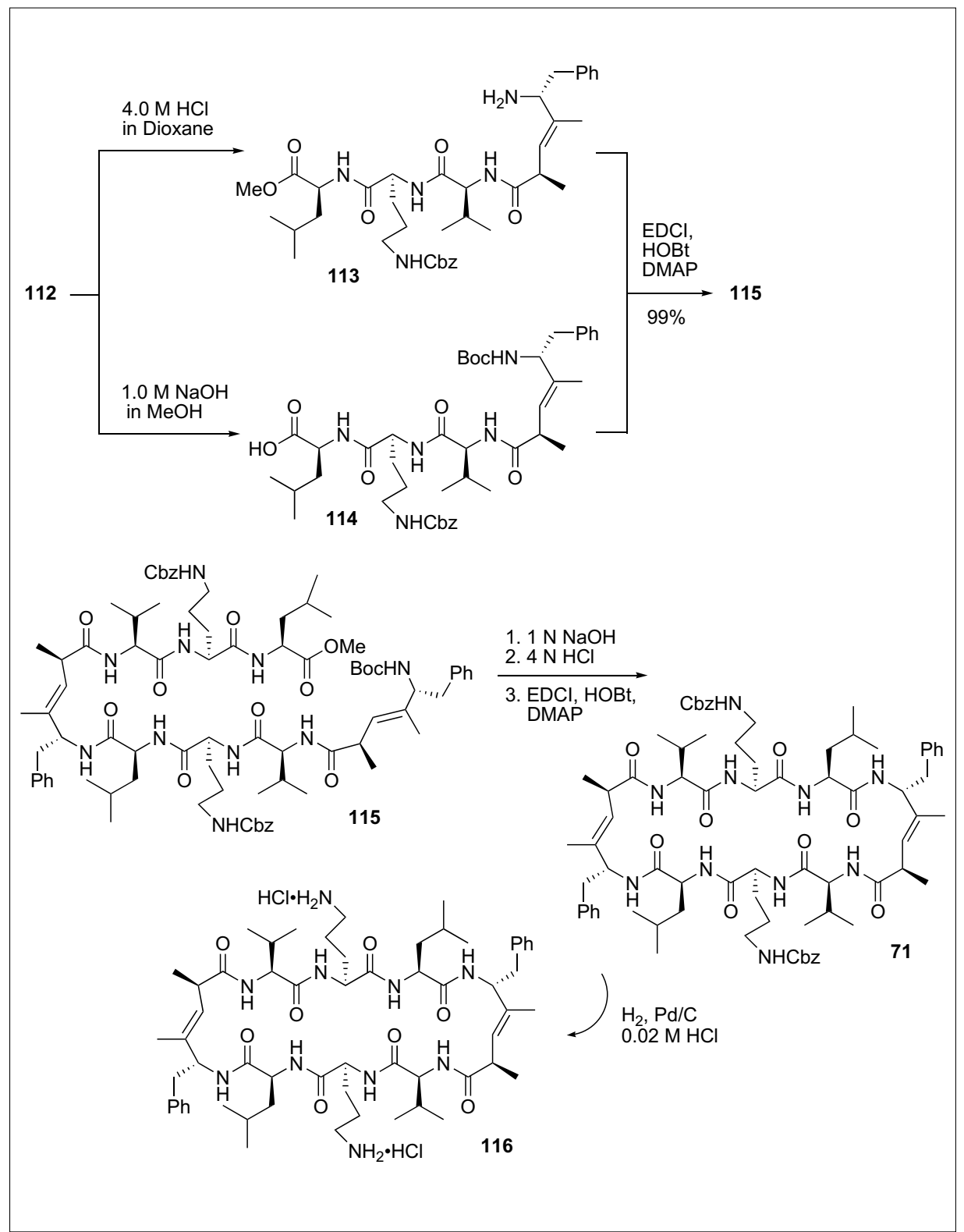

Scheme 15. Synthesis of a GS analog 116 with a trisubstituted alkene amide bond replacement in the $\mathrm{D}$-Phe-Pro $\beta$-turn sequence. moval of the Boc protecting group with 4 $\mathrm{N} \mathrm{HCl}$ in dioxane, followed by a one-pot macrolactamization, afforded the desired PLM 71 in $50 \%$ yield after purification with preparative $\mathrm{C}_{18}$ reverse phase HPLC. Furthermore, the two ornithine Cbz protecting groups were successfully removed by hydrogenation of $\mathbf{7 1}$ in the presence of $10 \% \mathrm{Pd} / \mathrm{C}$ in a $0.02 \mathrm{M} \mathrm{HCl} /$ methanol solution to afford 116

NMR and CD experiments were in full agreement with the promotion of the type II' $\beta$-turns found for GS at the D-Phe-Pro positions by the trisubstituted $(E)$-alkene dipeptide isosteric replacements in PLMs 71 and 116.

\section{PLM Design Validation: Biological Studies and Potential Therapeutic Applications}

The development of analogs of biologically active natural products and biopolymers ultimately has to pass the test of in vivo activity, therapeutic potential, or, at a minimum, deliver a level of activity and target selectivity that justifies use as a biological probe molecule. In addition to the microcidal activities displayed by our GS analogs, we were able to demonstrate a broad utility of GS-derived MPLs as mitochondrial targeting agents.

Our design of the 4-amino TEMPO (4-AT) derivative XJB-5-131 was inspired by the known affinity of the cyclopeptide antibiotic GS to bacterial membrane lipids. We hypothesized that the related ancestry and biochemical homologies between prokaryotes and endosymbiontic mitochondria would result in a similar affinity of gramicidin $\mathrm{S}$ to mitochondrial membranes and associated lipids over mammalian membrane components. Furthermore, our initial structure-activity relationships in the context of the synthesis of alkene isosteric replacements in GS demonstrated that the GS-derived mitochondrial targeting property could be preserved in shorter, acyclic fragments that retained the signature $\beta$-turn at the D-Phe-Pro position of the parent structure (Fig. 11).[28b,40] The enrichment factor of XJB-5-131 in mitochondria over the cytosol was determined to be about 600-fold.

Furthermore, XJB-5-131 was shown to prolong survival in a rodent model of hemorrhagic shock, mitigate oxidative stress, and preempt the mitochondrial pathway toward apoptosis. ${ }^{[41-44]}$ A 3rd generation approach toward alkene peptide isosteres based on zirconocene methodology developed in our laboratory was used for the synthesis of this compound (Scheme 16). ${ }^{[32,45,46]}$ This approach expands the $N$ tert-butane sulfinyl imine nucleophilic addition chemistry for the preparation of 


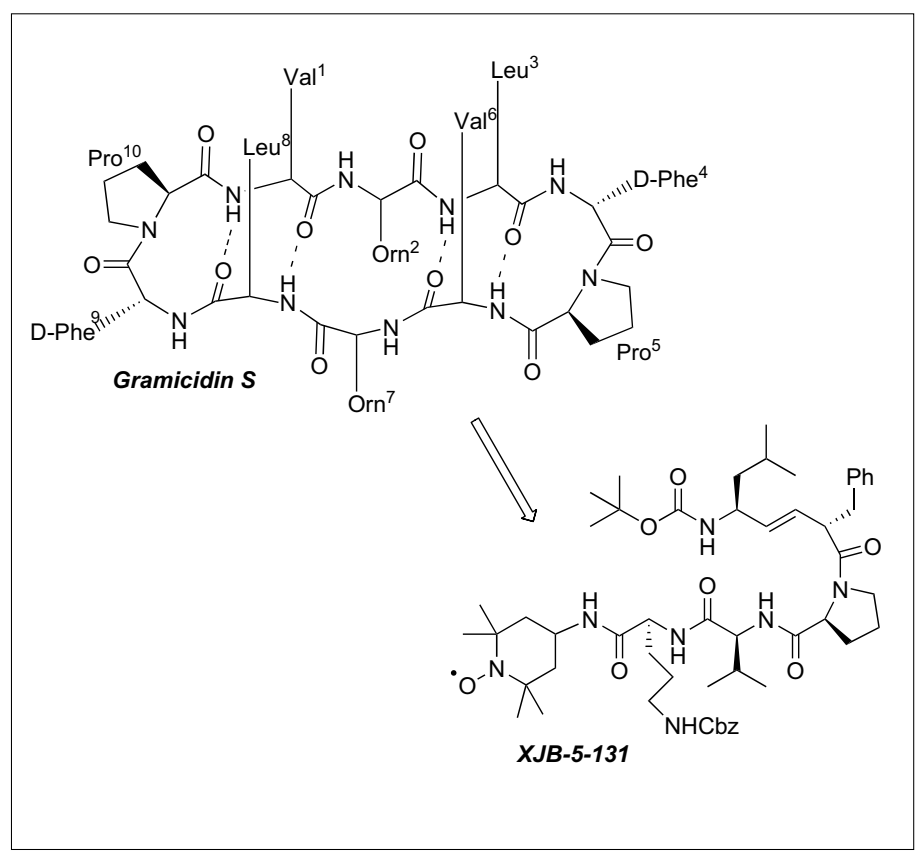

Fig. 11. Structure of GS-inspired XJB-5-131.
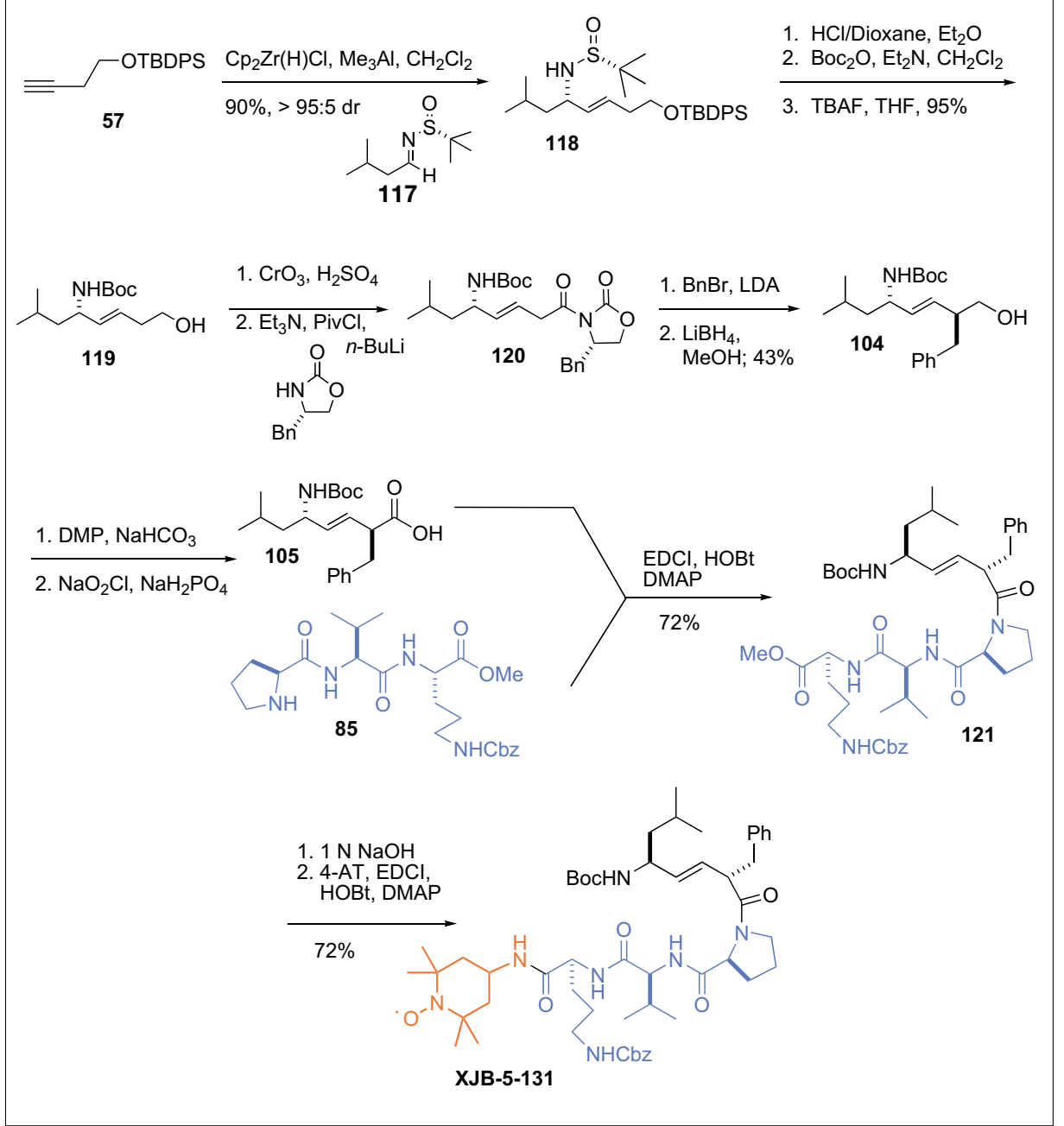

Scheme 16. Synthesis of XJB-5-131. The agent contains an ROS/RNS scavenger (red), a conformationally preorganized mitochondrial targeting unit (blue/black), and a peptide isostere motif that decreases $N$-terminal exopeptidase degradation (black). allylic amines, ${ }^{[47-49]}$ and we applied it to the preparation of $c a$. twelve analogs. A related PLM in this series demonstrated substantative in vivo radioprotective effects. ${ }^{[50]}$ In the course of optimizing the pharmacokinetic properties of XJB-5-131, we also recently identified a shorter sequence, JP4039, as a small molecular weight analog with remarkable anti-inflammatory and radioprotective properties. ${ }^{[51-53]}$ Studies for the development of additional mitochondrial targeting systems are actively being pursued in our laboratories.

\section{Acknowledgements}

Our work has been supported by Defense Advanced Research Projects Administration (DARPA contract W81XWH-05-2-0026) as well as grants from the U.S. Public Health Service National Institutes of Health (GM067082 and AI068021) and discretionary funds from Boehringer Ingelheim and Merck Research Laboratories. Dr. J. E. Davoren developed the improved synthesis of XJB-5131 shown in Scheme 16.

Received: June 5, 2009

[1] W. Yang, W. Lu, Y. Lu, M. Zhong, J. Sun, A. E. Thomas, J. M. Wilkinson, R. V. Fucini, M. Lam, M. Randal, X.-P. Shi, J. W. Jacobs, R. S. McDowell, E. M. Gordon, M. D. Ballinger, J. Med. Chem. 2006, 49, 839.

[2] C. S. Li, D. Deschenes, S. Desmarais, J.-P. Falgueyret, J. Y. Gauthier, D. B. Kimmel, S. Leger, F. Masse, M. E. McGrath, D. J. McKay, M. D. Percival, D. Riendeau, S. B. Rodan, M. Therien, V.-L. Truong, G. Wesolowski, R. Zamboni, W. C. Black, Bioorg. Med. Chem. Lett. 2006, 16, 1985.

[3] M. Zanda, New J. Chem. 2004, 28, 1401.

[4] S. Oishi, K. Miyamoto, A. Niida, M. Yamamoto, K. Ajito, H. Tamamura, A. Otaka, Y. Kuroda, A. Asai, N. Fujii, Tetrahedron 2006, 62, 1416.

[5] J. Kim, G. Hewitt, P. Carroll, S. M. Sieburth, J. Org. Chem. 2005, 70, 5781.

[6] a) M. Ordonez, C. Cativiela, Tetrahedron: Asymm. 2007, 18, 3; b) R. P. Cheng, S. H. Gellman, W. F. DeGrado, Chem. Rev. 2001, 101, 3219; c) D. J. Hill, M. J. Mio, R. B. Prince, T. S. Hughes, J. S. Moore, Chem. Rev. 2001, 101, 3893; d) D. Seebach, A. K. Beck, D. J. Bierbaum, Chem. Biodiversity 2004, 1, 1111.

[7] D. P. Walsh, Y.-T. Chang, Chem. Rev. 2006, 106, 2476.

[8] T. K. Sawyer, R. S. Bohacek, D. C. Dalgarno, C. J. Eyermann, N. Kawahata, C. A. Metcalf III, W. C. Shakespeare, R. Sundaramoorthi, Y. Wang, M. G. Yang, Mini-Rev. Med. Chem. 2002, 2, 475.

[9] I. Huc, Eur. J. Org. Chem. 2004, 17.

[10] a) D. Seebach, J. L. Matthews, Chem. Commun. 1997, 2015; b) D. Seebach, A. K. Beck, M. Brenner, C. Gaul, A. Heckel, Chimia 2001, 55, 831.

[11] T. L. Raguse, E. A. Porter, B. Weisblum, S. H. Gellman, J. Am. Chem. Soc. 2002, 124, 12774.

[12] A. J. Karlsson, W. C. Pomerantz, B. Weisblum, S. H. Gellman, S. P. Palecek, J. Am. Chem. Soc. 2006, 128, 12630.

[13] T. B. Potocky, J. Silvius, A. K. Menon, S. H. Gellman, ChemBioChem 2007, 8, 917.

[14] O. M. Stephens, S. Kim, B. D. Welch, M. E. Hodsdon, M. S. Kay, A. Schepartz, J. Am. Chem. Soc. 2005, 127, 13126.

[15] P. Chakraborty, U. Diederichsen, Chem. Eur. J. 2005, 11, 3207. 
[16] W. C. Pomerantz, N. L. Abbott, S. H. Gellman, J. Am. Chem. Soc. 2006, 128, 8730.

[17] a) A. Reichelt, S. F. Martin, Acc. Chem. Res. 2006, 39, 433; b) W. M. Kazmierski, T. P. Kenakin, K. S. Gudmundsson, Chem. Biol. Drug. Des. 2006, 67, 13; c) J. M. Sanderson, Org. Biomol. Chem. 2005, 3, 201; d) M. R. Pratt, C. R. Bertozzi, Chem. Soc. Rev. 2005, 34, 58; e) B. R. Peterson, Org. Biomol. Chem. 2005 3, 3607; f) V. Marx, Chem. Eng. News 2005, 17.

[18] For recent representative examples from our collaborative studies, see: a) F. Liu, D. Du, A A. Fuller, J. E. Davoren, P. Wipf, J. W. Kelly, M. Gruebele, Proc. Natl. Acad. Sci. USA 2008 105, 2369; b) A. A. Fuller, D. Du, F. Liu, J. E Davoren, G. Bhabha, G. Kroon, D. A. Case, H. J. Dyson, E. T. Powers, P. Wipf, M. Gruebele, J. W. Kelly, Proc. Natl. Acad. Sci. USA 2009 106, in press; c) M.-R. Lee, T. L. Raguse, M. Schinnerl, W. C. Pomerantz, X. Wang, P. Wipf, S. H. Gellman, Org. Lett. 2007, 9, 1801.

[19] A. Banerjee, E. Sergienko, S. Vasile, V. Gupta, K. Vuori, P. Wipf, Org. Lett. 2009, 11, 65.

[20] L. M. Jarvis, Chem. Eng. News 2006, 84, 23.

[21] G. A. Patani, E. J. LaVoie, Chem. Rev. 1996, 96, 3147

[22] a) K. Tomita, T. Narumi, A. Niida, S. Oishi, H. Ohno, N. Fujii, Biopolymers 2007, 88, 272; b) D. Wiktelius, K. Luthman, Org. Biomol. Chem. 2007, 5, 603; c) N. G. Bandur, K. Harms, U. Koert, Synthesis 2007, 2720; d) P. Wipf, J. Xiao, S. J. Geib, Adv. Synth. Cat. 2005, 347, 1605; e) P. Wipf, J. Xiao, Org. Lett. 2005, 7, 103; f) C. L. Jenkins, M. M. Vasbinder, S. J. Miller, R. T. Raines, Org. Lett. 2005, 7, 2619; g) Y. Fu, J. Bieschke, J. W. Kelly, J. Am. Chem. Soc. 2005 127, 15366.

[23] a) J. Vabeno, T. Lejon, C. U. Nielsen, B. Steffansen, W. Chen, H. Ouyang, R. T. Borchardt, K. Luthman, Med. Chem. 2004, 47, 1060; b) A. Dondoni, D. Perrone, Tetrahedron Lett. 1992, 33, 7259

[24] a) T. Lama, S. E. Del Valle, N. Genest, W. D. Lubell, Int. J. Peptide Res. Ther. 2007, 13, 355 b) A. G. Myers, J. K. Barbay, B. Zhong, J. Am. Chem. Soc. 2001, 123, 7207; c) Y. Aoyagi, R. M. Williams, Tetrahedron 1998, 54, 10419.

[25] G. Righi, S. Ronconi, C. Bonini, Eur. J. Org. Chem. 2002, 1573

[26] R. C. Reid, L. K. Pattenden, J. D. A. Tyndall, J. L. Martin, T. Walsh, D. P. Fairlie, J. Med. Chem. 2004, 47, 1641.

[27] K. Leftheris, T. Kline, G. D. Vite, Y. H. Cho R. S. Bhide, D. V. Patel, M. M. Patel, R. J. Schmidt, H. N. Weller, M. L. Andahazy, J. M. Carboni, J. L. Gullo-Brown, F. Y. F. Lee, C. Ricca, W. C. Rose, N. Yan, M. Barbacid, J. T. Hunt, C. A. Meyers, B. R. Seizinger, R. Zahler, V. Manne, J. Med. Chem. 1996, 39, 224.

[28] a) P. Wipf, P. C. Fritch, J. Org. Chem. 1994, 59, 4875; b) P. Wipf, T. Henninger, J. Org. Chem.
1997, 62, 1586; c) P. Wipf, T. C. Henninger, S. J. Geib, J. Org. Chem. 1998, 63, 6088; d) T. Henninger, P. Wipf, in 'Methods in Molecular Medicine: Peptidomimetics', Eds. J. M. Walker, W. M. Kazmierski, Humana Press, Totowa, 1999, Vol 23, pp 125-136; e) Y. Mu, C. R. J. Stephenson, C. Kendall, S. P. S. Saini, D. Toma, S. Ren, H. Cai, S. C. Strom, B. W. Day, P. Wipf, W. Xie, Mol. Pharm. 2005, 68, 403; f) P. Wipf, C. R. J. Stephenson, Org. Lett. 2005, 7, 1137; g) P. Wipf, S. Werner, G. H. C. Woo, C. R. J. Stephenson, M. A. A. Walczak, C. M. Coleman, L. A. Twining, Tetrahedron 2005, 61, 11488; h) P. Wipf, J. Xiao, J. Jiang, N. A. Belikova, V. A. Tyurin, M. P. Fink, V. E. Kagan, J. Am. Chem. Soc. 2005, 127, 12460; i) N. Levinson, R. Hinman, A. Patil, C. R. J. Stephenson, S. Werner, G. H. C. Woo, J. Xiao, P. Wipf, K. W. Lynch, RNA 2006, 12, 925; j) Z. Chen, Y. Yang, S. Werner, P. Wipf, S. G. Weber, J. Am. Chem. Soc. 2006, 128, 2208.

[29] a) Y. Nakamura, M. Okada, M. Koura, M. Tojo, A. Saito, A. Sato, T. Taguchi, J. Fluorine Chem. 2006, 127, 627; b) H. Tamamura, K. Hiramatsu, S. Ueda, Z. Wang, S. Kusano, S. Terakubo, J. O. Trent, S. C. Peiper, N. Yamamoto, H. Nakashima, A. Otaka, N. Fujii, J. Med. Chem. 2005, 48, 380; c) X. J. Wang, S. A. Hart, B. Xu, M. D. Mason, J. R. Goodell, F. A. Etzkorn, J. Org. Chem. 2003, 68, 2343; d) P. Van der Veken, I. Kertesz, K. Senten, A. Haemers, K. Augustyns, Tetrahedron Lett. 2003, 44, 6231; e) H. Tamamura, K. Hiramatsu, K. Miyamoto, A. Omagari, S. Oishi, H. Nakashima, N. Yamamoto, Y. Kuroda, T. Nakagawa, A. Otaka, N. Fujii, Bioorg. Med. Chem. Lett. 2002, 12, 923.

[30] a) J. Xiao, B. Weisblum, P. Wipf, J. Am. Chem. Soc. 2005, 127, 5742; b) J. Xiao, B. Weisblum, P. Wipf, Org. Lett. 2006, 8, 4731.

[31] T. Ibuka, K. Nakai, H. Habashita, Y. Hotta, N. Fujii, N. Mimura, Y. Miwa, T. Taga, Y. Yamamoto, Angew. Chem. Int. Ed. Engl. 1994, 33, 652.

[32] P. Wipf, C. Kendall, C. R. J. Stephenson, J. Am. Chem. Soc. 2003, 125, 761 .

[33] a) Q. Chen, S. Wu, J. Chem. Soc., Chem. Commun. 1989, 705; b) X.-S. Fei, W.-S. Tian, Q.-Y. Chen, J. Chem. Soc., Perkin Trans. 1 1998, 1139

[34] M. Hagihara, N. J. Anthony, T. J. Stout, J. Clardy, S. L. Schreiber, J. Am. Chem. Soc. 1992, $114,6568$.

[35] a) S. T. Phillips, M. Rezac, U. Abel, M Kossenjans, P. A. Bartlett, J. Am. Chem. Soc. 2002, 124, 58; b) J. S. Nowick, Acc. Chem. Res. 1999, 32, 287; c) A. B. Smith III, M. C. Guzman, P. A. Sprengeler, T. P. Keenan, R. C. Holcomb, J. L. Wood, P. J. Carroll, R. Hirschmann, J. Am. Chem. Soc 1994, 116, 9947.

[36] D. L. Lee, R. S. Hodges, Biopolymers 2003, 71, 28
[37] G. M. Grotenbreg, A. E. M. Buizert, A. L. Llamas-Saiz, E. Spalburg, P. A. V. Van Hooft, A. J. De Neeling, D. Noort, M. J. Van Raaij, G. A. Van der Marel, H. S. Overkleeft, M. Overhand, J. Am. Chem. Soc. 2006, 128, 7559.

[38] a) M. Tamaki, S. Akabori, I. Muramatsu, Bull. Chem. Soc. Jpn. 1993, 66, 3113; b) R. W. Woody, in 'Circular Dichroism', Eds. K. Nakanishi, N. Berova, R. W. Woody, chap. 17, p. 473-496, VCH, New York, 1994.

[39] A. Côté, A. A. Boezio, A. B. Charette, Proc. Nat. Acad. Sci. USA 2004, 101, 5405.

[40] A. T. Hoye, J. E. Davoren, P. Wipf, M. P. Fink, V. E. Kagan, Acc. Chem. Res. 2008, 41, 87.

[41] C. A. Macias, J. W. Chiao, J. Xiao, D. S. Arora, Y. Y. Tyurina, R. L. Delude, P. Wipf, V. E. Kagan, M. P. Fink, Ann. Surg. 2007, 245, 305.

[42] J. Jiang, I. Kurnikov, N. A. Belikova, J. Xiao, Q. Zhao, A. A. Amoscato, R. Braslau, A. Studer, M. P. Fink, J. S. Greenberger, P. Wipf, V. E. Kagan, J. Pharmacol. Exp. Ther. 2007, 320, 1050.

[43] V. E. Kagan, A. Bayir, H. Bayir, D. Stoyanovsky, G. G. Borisenko, Y. Y. Tyurina, P. Wipf, J Atkinson, J. S. Greenberger, R. S. Chapkin, N. A. Belikova, Mol. Nutr. Food Res. 2009, 53, 104.

[44] M. P. Fink, C. A. Macias, J. Xiao, Y. Y. Tyurina, J. Jiang, N. Belikova, R. L. Delude, J. S Greenberger, V. E. Kagan, P. Wipf, Biochem. Pharmacol. 2007, 74, 801.

[45] P. Wipf, C. Kendall, Top. Organomet. Chem. 2004, 8,1 .

[46] A. Fuller, D. Du, F. Liu, J. E. Davoren, G Bhabha, G. Kroon, D. A. Case, H. J. Dyson, E. T. Powers, P. Wipf, M. Gruebele, J. W. Kelly Jeffery, Proc. Natl. Acad. Sci USA 2009, 106 11067.

[47] D. A. Cogan, G. Liu, J. Ellman, Tetrahedron 1999, 55, 8883.

[48] P. Wipf, R. L. Nunes, S. Ribe, Helv. Chim. Acta 2002, 85, 3478 .

[49] P. Wipf, R. L. Nunes, Tetahedron 1999, 60 , 1269.

[50] J. Jiang, N. A. Belikova, A. T. Hoye, Q. Zhao, M. W. Epperly, J. S. Greenberger, P. Wipf, V. E. Kagan, Int. J. Radiat. Oncol. Biol. Phys. 2008, $70,816$.

[51] J. G. Pierce, $\mathrm{PhD}$ Thesis, University of Pittsburgh, 2008

[52] M. P. Fink, P. Wipf, 'Use of mitochondriatargeted electron scavengers as antiinflammatory agents', US Patent Application, US2009042808, 2009.

[53] J. G. Pierce, M. W. Epperly, J. S. Greenberger, P. Wipf, V. E. Kagan, unpublished results. 